\title{
Remote Loading of 64Cu2+ into Liposomes without the Use of Ion Transport
} Enhancers

Henriksen, Jonas Rosager; Petersen, Anncatrine Luisa; Hansen, Anders Elias; Frankær, Christian Grundahl; Harris, Pernille; Elema, Dennis Ringkjøbing; Kristensen, Annemarie T.; Kjær, Andreas ; Andresen, Thomas Lars

\section{Published in:}

A C S Applied Materials and Interfaces

Link to article, DOI:

10.1021/acsami.5b04612

Publication date:

2015

Document Version

Peer reviewed version

Link back to DTU Orbit

Citation (APA):

Henriksen, J.'R., Petersen, A. L., Hansen, A. E., Frankæz, C.2G., Harris, P., Elema, D. R., Kristensen, A. T., Kjær, A., \& Andresen, T. L. (2015). Remote Loading of ${ }^{2} \mathrm{Cu}^{2+}$ into Liposomes without the Use of lon Transport Enhancers. A C S Applied Materials and Interfaces, 7(41), 22796-22806.

https://doi.org/10.1021/acsami.5b04612

\section{General rights}

Copyright and moral rights for the publications made accessible in the public portal are retained by the authors and/or other copyright owners and it is a condition of accessing publications that users recognise and abide by the legal requirements associated with these rights.

- Users may download and print one copy of any publication from the public portal for the purpose of private study or research.

- You may not further distribute the material or use it for any profit-making activity or commercial gain

- You may freely distribute the URL identifying the publication in the public portal 


\title{
Remote Loading of ${ }^{64} \mathrm{Cu}^{2+}$ into Liposomes without use of Ion Transport Enhancers
}

\author{
Jonas R. Henriksen ${ }^{1,5}$, Anncatrine L. Petersen ${ }^{2,5}$, Anders E. Hansen ${ }^{2,3,5}$, Christian G. Frankar ${ }^{1}$, Pernille
} Harris $^{1}$,Dennis R. Elema ${ }^{4,5}$, Annemarie T. Kristensen ${ }^{6}$, Andreas Kjar ${ }^{3}$ and Thomas L. Andresen ${ }^{2,5^{*}}$

\footnotetext{
${ }^{1}$ Technical University of Denmark, Department of Chemistry, Building 206, 2800 Lyngby, Denmark;

${ }^{2}$ Technical University of Denmark, Department of Micro- and Nanotechnology, Building 423, 2800

Lyngby, Denmark; ${ }^{3}$ University of Copenhagen, Faculty of Health Sciences, Department of Clinical Physiology, Nuclear Medicine \& PET and Cluster for Molecular Imaging, Rigshospitalet and University of Copenhagen, Blegdamsvej 3, 2200 Copenhagen N, Denmark; ${ }^{4}$ Technical University of Denmark, DTU Nutech, Hevesy Laboratory, Frederiksborgvej 399, 4000 Roskilde, Denmark; ${ }^{5}$ Center for Nanomedicine and Theranostics, Technical University of Denmark, 2800 Lyngby, Denmark; ${ }^{6}$ Department of Veterinary Clinical and Animal Sciences, Faculty of Health and Medical Sciences, University of Copenhagen, Dyrlægevej 16, 1870 Frederiksberg C, Denmark.
}

*Corresponding author: Tel: +45 45258168; E-mail: thomas.andresen@ nanotech.dtu.dk 


\title{
Keywords
}

Nanoparticles, remote loading, ion permeability, diagnostic, positron emission tomography, molecular imaging

\begin{abstract}
Due to low ion permeability of lipid bilayers, it has been and still is common practice to use transporter molecules such as ionophores or lipophilic chelators to increase trans-membrane diffusion rates and loading efficiencies of radionuclides into liposomes. Here, we report a novel and very simple method for loading the positron emitter ${ }^{64} \mathrm{Cu}^{2+}$ into liposomes, which is important for in vivo positron emission tomography (PET) imaging. By this approach, copper is added to liposomes entrapping a chelator, which causes spontaneous diffusion of copper across the lipid bilayer where it is trapped. Using this method, we achieve highly efficient ${ }^{64} \mathrm{Cu}^{2+}$ loading, high radionuclide retention, and favorable loading kinetics, excluding use of transporter molecule additives. We investigate the molecular coordination of entrapped copper using X-ray absorption spectroscopy, and demonstrate high adaptability of the loading method to different lipid formulations. We demonstrate high in vivo stability of ${ }^{64} \mathrm{Cu}$-liposomes in a canine cancer model and evaluate tumor accumulation in mice using PET imaging. With this work, it is demonstrated that copper ions are capable of crossing a lipid membrane unassisted. This method is highly valuable for characterizing in vivo performance of liposome-based nanomedicine with great potential in diagnostic imaging applications.
\end{abstract}




\section{Introduction}

In recent years, the use of imaging in cancer diagnostics and treatment planning has increased considerably. New companion diagnostic agents are emerging ${ }^{1,2}$ that can be used to select patients that will be responsive to a specific treatment. Methods for radiolabeling of nanodrugs are particularly interesting as nanomedicines provide new possibilities in companion diagnostics and personalized medicine. A number of radiolabeling methods have already been developed for preparing radioactive liposomes, ${ }^{3-13}$ where the main focus has been on single-photon emission computed tomography (SPECT) isotopes. Labeling of liposomes with PET isotopes can provide high-resolution and superior quantitative information on the pharmacokinetics and biodistribution of potential nanodrugs, which can be of high value during drug development and for clinical translation. ${ }^{1,2}$ Among the different methods for preparing radioactive liposomes, remote loading of radionuclides into the aqueous core of liposomes seems to provide the greatest in vivo stability. The radionuclides reside in a protected environment inside the liposome, which reduce the risk of transmetalation after administration, in comparison to radionuclide surface chelation. ${ }^{5,6}$ In addition, no liposomal surface alterations are imposed when loading radionuclides into the aqueous core in contrast to surface chelation. This is often important when investigating the in vivo behaviour of liposomal formulations with specific physical-chemical surface properties.

During the last 30 years, ionophores and lipophilic chelators have been used for remote loading of radionuclides such as ${ }^{111} \mathrm{In}^{3+},{ }^{67 / 68} \mathrm{Ga}^{3+},{ }^{64} \mathrm{Cu}^{2+},{ }^{123 / 124} \mathrm{I}^{-},{ }^{177} \mathrm{Lu}^{3+}$ and ${ }^{99 \mathrm{~m}} \mathrm{TcO}_{4}{ }^{-}$into liposomes ${ }^{7-12}$ So far, only a few ionophore assisted loading (IAL) procedures have been developed for liposomal PET imaging applications. ${ }^{1,12,13}$ Despite the generally high loading efficiencies, high radionuclide retention, rapid loading kinetics and successful in vivo liposomal performance there are disadvantages of using transporter molecules such as ionophores or lipophilic chelators (hereafter referred to as ionophores as a common term) for remote loading of radionuclides into liposomes. One drawback to consider is the penalty in Gibbs free energy, which derives from stripping the radionuclide from the ionophore upon transfer to the liposome-entrapped chelator (Figure 1, right). 


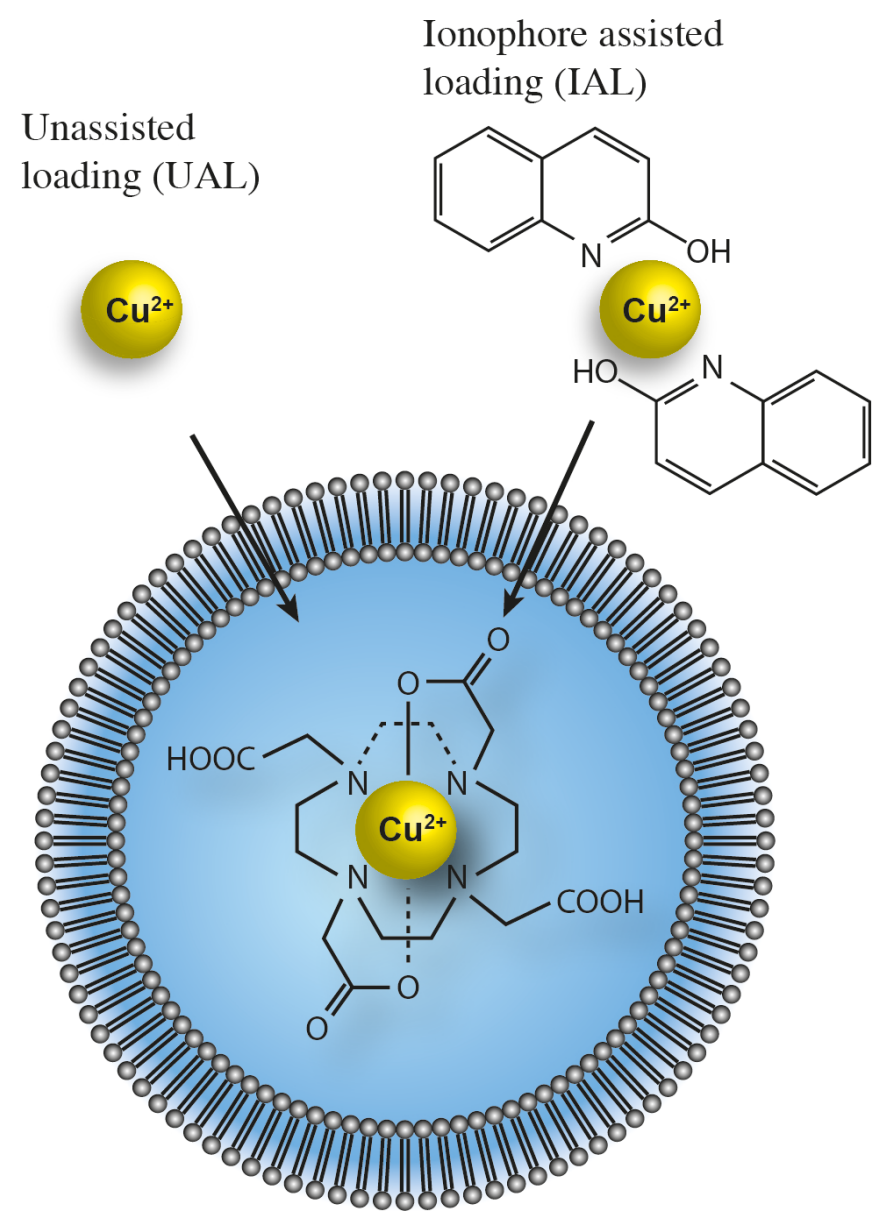

Figure 1. Loading of $\mathrm{Cu}^{2+}$ into liposomes. After addition of $\mathrm{Cu}^{2+}$ to a liposome solution, $\mathrm{Cu}^{2+}$ can pass the lipid bilayer either unassisted (left) or assisted (right) by an ionophore such as 2-hydroxyquinoline (2HQ). $\mathrm{Cu}^{2+}$ then forms a complex with the encapsulated chelator (DOTA) and is hereby trapped inside the liposome.

This effect reduces the thermodynamic driving force for forming the radionuclide-chelator complex inside the liposome and thereby potentially the loading efficiency. Thus, choosing a correctly matched entrapped chelator and ionophore with respect to copper affinity, is essential for obtaining a thermodynamic stable encapsulation of the radionuclide ${ }^{12}$ when using the IAL method. Otherwise, the radionuclide may be prematurely released after in vivo administration, which can result in erroneous estimation of the distribution of the liposomes and lowering of PET image quality. Furthermore, ionophores can be toxic to 
humans as a consequence of their high lipophilicity and ability to disrupt ionic gradients of cells leading to disturbances in physiological functions. ${ }^{14}$ Hence, ionophores used for loading of liposomes with radionuclides has to be removed by purification after preparation, which is not ideal for PET isotopes due to their short half-life (e.g. ${ }^{64} \mathrm{Cu}$ has $12.7 \mathrm{~h}$ half-life).

Several research groups have investigated the membrane permeability of anions and cations. ${ }^{15-18}$ From these studies, low ion permeability of phospholipid bilayers, such as liposomes, is expected to result in highly unfavorable loading kinetics of charged ion species. Common practice is therefore to use ionophores to increase the trans-membrane ion diffusion rate, and thereby improve the loading kinetics of charged ions such as radionuclides into liposomes. ${ }^{7-13}$ Despite previous knowledge and findings within this field, the present work describes a novel loading method of the PET radionuclide ${ }^{64} \mathrm{Cu}^{2+}$ into liposomes, excluding the use of ionophores (an unassisted loading). In this method, ${ }^{64} \mathrm{Cu}^{2+}$ (or copper) is added to preformed liposomes entrapping a high affinity copper chelator (Figure 1, left). The aqueous core of these liposomes is depleted from free copper due to presence of the entrapped chelator. This establishes a strong trans-membrane copper gradient, which facilitate diffusion of copper ions across the lipid bilayer. Once inside, the encapsulated chelator traps copper. The fact that ionophores can be avoided in the current unassisted loading (UAL) method, presents a major advancement with respect to radionuclide entrapment stability and simplicity of loading compared to other and our previous published methods. ${ }^{12}$ It is furthermore highly surprising due to the general belief that cation diffusion across lipid bilayers is very slow.

In the present work, the loading efficiency of the new UAL method is compared to our previously published method, which relies on the use of 2-hydroxyquinoline (2HQ) for ionophore assisted transport of $\mathrm{Cu}^{2+} \cdot{ }^{2}$ In order to characterize and optimize the conditions at which the loading is most favorable, the loading efficiency and loading kinetics, of the UAL method, is investigated as function of temperature. The UAL method is furthermore tested for several liposome formulations, including ligand-targeted, pegylated, non-pegylated, gel or fluid like, cholesterol rich or cholesterol depleted, cationic, anionic and 
zwitterionic lipid compositions. The loading of ${ }^{64} \mathrm{Cu}^{2+}$ is analyzed using size exclusion chromatography (SEC) and radio thin layer chromatography (radio-TLC).

The UAL method is investigated further by analysis of liposomes loaded with non-radioactive copper. The loading efficiency of these liposomes is analyzed by ICP-MS and ligands coordinating the liposome-entrapped copper are explored by X-ray absorption spectroscopy.

The in vivo performance of ${ }^{64} \mathrm{Cu}$-loaded liposomes is evaluated in tumor-bearing mice and in a canine cancer model. Biodistribution and tumor accumulation is quantified using combined PET/computed tomography (CT) imaging.

\section{Materials and Methods}

\subsection{Materials}

1,2-dipalmitoyl-sn-glycero-3-phospho-(1'-rac-glycerol) （DPPG), 1,2-dipalmitoyl-sn-glycero-3phosphocholine (DPPC), 1-palmitoyl-2-oleoyl-sn-glycero-3-phospho-(1'-rac-glycerol) (POPG), 1palmitoyl-2-oleoyl-sn-glycero-3-phosphocholine (POPC), 1,2-stearoyl-3-trimethylammonium-propane (DSTAP), hydrogenated soy phosphatidylcholine (HSPC), 1,2-distearoyl-sn-glycero-3-phosphocholine (DSPC), cholesterol (CHOL), 1,2-distearoyl-sn-glycero-3-phosphoethanolamine- $N$-[methoxy (polyethylene glycol)-2000] (DSPE-PEG ${ }_{2000}$ ) and 1,2-distearoyl-sn-glycero-3-phosphoethanolamine- $N$ [methoxy (polyethylene glycol)-5000]-Folate (DSPE-PEG ${ }_{5000}$-Folate) were purchased from Avanti Polar Lipids (Alabama, USA). The freeze-dried lipid mixture (stealth formulation): HSPC:CHOL:DSPE$\mathrm{PEG}_{2000}$ in the molar ratio (56.5:38.2:5.3) was purchased from Lipoid ${ }^{\circledR} \mathrm{GmbH}$ (Ludwigshafen, Germany). DSPE-PEG ${ }_{2000}$-RGD was synthesized in our own lab. 1,4,7,10-tetra-azacyclododecane-1,4,7,10tetraacetic acid (DOTA) was purchased from Macrocyclics (Dallas, USA). The buffer 4-(2hydroxyethyl)piperazine-1-ethanesulfonic acid (HEPES) and all other solvents and chemicals were purchased from Sigma Aldrich (Schnelldorf, Germany) and were used without further purification. 
Amicon Ultra-15 centrifugal filter units were purchased from Millipore (Denmark). TLC-plates Silica gel $60 \mathrm{~F}_{254}$ were purchased from Merck (Darmstadt, Germany). Mini-extruder was purchased from Avanti Polar Lipids (Alabama, USA). LIPEX Thermobarrel Pressure Extruder (10 mL) was purchased from Northern Lipids (Burnaby, Canada) and the Minimate ${ }^{\mathrm{TM}}$ tangential flow filtration system was purchased from Pall Corporation (Canada). Human serum was purchased from Sigma Aldrich (Schnelldorf, Germany). Mice and dog blood was taped from animals into Hirudine tubes, and the plasma fraction was collected.

\section{2. ${ }^{64} \mathrm{Cu}$ production}

Copper-64 was produced on a PETtrace cyclotron (GE Healthcare). The production of ${ }^{64} \mathrm{Cu}^{2+}$ was carried out via the ${ }^{64} \mathrm{Ni}(\mathrm{p}, \mathrm{n}){ }^{64} \mathrm{Cu}$ nuclear reaction as described previously. ${ }^{12} \mathrm{~A}$ specific activity of $3.3 \mathrm{TBq} / \mu \mathrm{mol}$ $(\mathrm{Cu})$ was achieved on average corresponding to $36 \%$ radioactive $\mathrm{Cu}$ nuclides $\left({ }^{64} \mathrm{Cu} / \mathrm{Cu}\right)$. The ${ }^{64} \mathrm{CuCl}_{2}$ was isolated by evaporation of aqueous $1 \mathrm{M} \mathrm{HCl}$ to dryness once added to a vial and used hereafter for remote loading of liposomes.

\subsection{Preparation of liposomes}

Chelator-containing liposomes were prepared as follow. The lipids were mixed in a chloroform:methanol (9:1) mixture and dried to a lipid-film under a gentle stream of nitrogen. Organic solvent residues were removed under reduced pressure overnight. As an exception, the HSPC:CHOL:DSPE-PEG 2000 (56.5:38.2:5.3) lipid formulation (stealth formulation) was prepared directly from the freeze-dried powder. The lipid-film or the powder was dispersed by adding a hydration buffer (10 mM HEPES, 150 $\mathrm{mM} \mathrm{NaCl})$ containing the chelator, DOTA $(10 \mathrm{mM})$. Hydration buffers were adjusted to either $\mathrm{pH} 4.0$ or 7.4 using $\mathrm{NaOH}$ and/or $\mathrm{HCl}$ resulting in an osmolarity of 330-380 mOsm $/ \mathrm{kg}$. Lipid suspensions were prepared at $50-65 \mathrm{mM}$ and hydrated at $65^{\circ} \mathrm{C}$ for $60 \mathrm{~min}$. Multi-lamellar vesicles (MLVs) were sized to 
large unilamellar vesicles (LUVs) by multiple extrusions through $100 \mathrm{~nm}$ polycarbonate filters using an Avanti mini-extruder or a LIPEX Thermobarrel Pressure Extruder (at 10-15 bar nitrogen).

Un-encapsulated DOTA was removed by repeated buffer exchange using Amicon Ultra-15 centrifugal filter units (100 kDa cutoff) exchanging the external buffer with a HEPES buffer (10 mM, 150 $\mathrm{mM} \mathrm{NaCl}, \mathrm{pH} 7.4,295 \mathrm{mOsm} / \mathrm{kg})$. In brief, $0.5 \mathrm{~mL}$ liposomes $(50 \mathrm{mM})$ were diluted to a total volume of $12 \mathrm{~mL}$ using HEPES buffer, and $11 \mathrm{~mL}$ were spun through the filter. The spin filtration was repeated four times, and the purified liposomes were collected. It is important to note, that repeated filtration is crucial for achieving high loading efficiency $(>95 \%)$ and fast loading kinetics, since the presence of chelating components on the liposome exterior lowers the copper transmembrane gradient, which slows down the loading kinetics and reduces the overall loading efficiency. The HSPC:CHOL:DSPE-PEG ${ }_{2000}$ (56.5:38.2:5.3) liposome formulation was as an exception purified using a Minimate ${ }^{\text {TM }}$ tangential flow filtration system.

Empty liposomes were prepared as follow. The lipid-film or powder was dispersed in aqueous buffer (10 mM HEPES, $150 \mathrm{mM} \mathrm{NaCl}, \mathrm{pH} \mathrm{7.4,} 295 \mathrm{mOsm} / \mathrm{kg})$. The lipid suspension was hydrated at $65^{\circ} \mathrm{C}$ for $60 \mathrm{~min}$. MLVs were sized to LUVs by multiple extrusions through $100 \mathrm{~nm}$ polycarbonate filters using an Avanti mini-extruder or a LIPEX Thermobarrel Pressure Extruder (at 10-15 bar nitrogen).

All liposome preparations were analyzed on size and zeta-potential using a Zeta Potential analyzer (ZetaPALS, Brookhaven, SE).

\subsection{Unassisted loading (UAL) of ${ }^{64} \mathrm{Cu}$ into liposomes}

Purified chelator-containing liposomes $(0.5-5.0 \mathrm{~mL}, 5-50 \mathrm{mM}$, internal $\mathrm{pH}$ 7.4) were added to a capped vial containing radioactive ${ }^{64} \mathrm{CuCl}_{2}(50-1500 \mathrm{MBq})$ in either dry or solvated form (in HEPES buffer). The sample was constantly stirred in a thermostatted lead-container during incubation. Unassisted loading 
(UAL) was conducted by sample incubation for $60-75 \mathrm{~min}$ at $25-55^{\circ} \mathrm{C}$. Formulations used for in vivo experiments were loaded at $55^{\circ} \mathrm{C}$ for $75 \mathrm{~min}$.

\subsection{Ionophore assisted loading (IAL) of ${ }^{64} \mathrm{Cu}^{2+}$ into liposomes}

In experiments using the ionophore 2-hydroxyquinoline (2HQ) for ionophore assisted loading (IAL) of ${ }^{64} \mathrm{Cu}^{2+}$ into chelator-containing liposomes, $10 \mu \mathrm{L} 2 \mathrm{HQ}$ in MilliQ water $\left(\mathrm{C}_{2 \mathrm{HQ}}=0.314 \mathrm{mM}\right)$ were added to the vial containing radioactive ${ }^{64} \mathrm{Cu}^{2+}$ prior to addition of chelator-containing liposomes as previously reported. ${ }^{12}$ Subsequently, purified chelator-containing liposomes (internal $\mathrm{pH} 4.0$ ) were added, and loading proceeded as described for the UAL method.

\section{7. ${ }^{64} \mathrm{Cu}^{2+}$ loading efficiency measured by size exclusion chromatography (SEC)}

${ }^{64} \mathrm{Cu}^{2+}$ loading efficiency was measured using size exclusion chromatography (SEC). The fraction of unentrapped ${ }^{64} \mathrm{Cu}$-DOTA, in the ${ }^{64} \mathrm{Cu}$-liposome solution, was quantified by separating ${ }^{64} \mathrm{Cu}$-DOTA from ${ }^{64} \mathrm{Cu}$-liposomes using a Sephadex G-25 column $(1 \mathrm{x} 25 \mathrm{~cm})$ eluted with a HEPES buffer $(10 \mathrm{mM}, 150$ $\mathrm{mM} \mathrm{NaCl}, \mathrm{pH} 7.4)$ with an injection volume of $500 \mu \mathrm{L}$ and a flow rate of $4 \mathrm{~mL} / \mathrm{min}$. The ${ }^{64} \mathrm{Cu}$-liposomal fraction was collected between 20-70 min and the ${ }^{64} \mathrm{Cu}$-DOTA or ${ }^{64} \mathrm{Cu}(2 \mathrm{HQ})_{2}$ fraction between $70-100$ min. An inline radioactivity detector was used for monitoring the SEC elution profile. The radioactivity in the liposomal fraction $\left(A_{l i p}\right)$ as well as the total sample activity $\left(A_{t o t, S E C}\right)$ was measured in a dose calibrator (Veenstra VDC-505). The loading efficiency was calculated as the ratio of the decay-corrected liposomal fraction and total sample activity, $\% \operatorname{load}_{\mathrm{SEC}}=2 \mathrm{~A}_{\text {lip }} \exp \left(\Delta \mathrm{t} / \mathrm{T}_{1 / 2}\right) / \mathrm{A}_{\mathrm{tot}, \mathrm{SEC}}$, where $\Delta t \sim 70-80 \mathrm{~min}$ is the time difference between the measurement of $A_{\text {lip }}$ and $A_{t o t}$, and $T_{1 / 2}=12.7 \mathrm{~h}$ is the half-life of ${ }^{64} \mathrm{Cu}$.

The loading efficiency of DSPC:CHOL:DSPE-PEG 2000 (55:40:10) liposomes entrapping DOTA was investigated using SEC. The loading experiment was conducted at 30,40 and $50^{\circ} \mathrm{C}$ using the new 
UAL method and our previously reported IAL method. ${ }^{12}$ Empty liposomes composed of DSPC:CHOL:DSPE-PEG $2000(55: 40: 10)$ were included as control in this study.

\section{8. ${ }^{64} \mathrm{Cu}^{2+}$ loading efficiency and kinetics measured by thin layer chromatography (radio-TLC)}

Free ${ }^{64} \mathrm{Cu}^{2+}$ binds to the Sephadex column and hence cannot be quantified by SEC. The fraction of free ${ }^{64} \mathrm{Cu}^{2+}$ in the ${ }^{64} \mathrm{Cu}$-liposome solution was therefore quantified by separation of ${ }^{64} \mathrm{Cu}$-DOTA and ${ }^{64} \mathrm{Cu}^{2+}$ by radio-TLC. Briefly, $2 \mu \mathrm{L}$ sample was spotted on a TLC plate (Silica gel $60 \mathrm{~F}_{254}$ ) and $10 \%$ aqueous ammonium acetate:methanol (50:50) was used as eluent. The retention factor $\left(\mathrm{R}_{\mathrm{f}}\right)$ of ${ }^{64} \mathrm{Cu}$-DOTA was 0.30.4, while ${ }^{64} \mathrm{Cu}^{2+}$ remains at the origin $\left(\mathrm{R}_{\mathrm{f}}=0\right)$. The TLC plate was read by a radio-TLC scanner (MiniGita Star GM, Raytest) or a Phosphor-imager (Cyclone Plus, Perkin Elmer). The radioactive peaks were integrated using associated computer software. The loading efficiency was calculated as $\%_{\text {load }}$ TLC $=A_{\text {Cu-DotA }} / A_{\text {tot }, T L C}$, where $A_{\text {Cu-DOTA }}$ is the ${ }^{64} \mathrm{Cu}$-DOTA TLC peak activity and $A_{\text {tot }, T L C}$ is the total ${ }^{64} \mathrm{Cu}^{2+}$ radioactivity deposited on the TLC plate. Since the ${ }^{64} \mathrm{Cu}$-liposomes collapse once dried on the TLC silica gel, the ${ }^{64} \mathrm{Cu}$-DOTA TLC-peak corresponds to the total radioactivity associated with DOTA in the sample (including encapsulated and un-encapsulated ${ }^{64} \mathrm{Cu}$-DOTA if present).

The loading kinetics of HSPC:CHOL:DSPE-PEG ${ }_{2000}$ (56.5:38.2:5.3) liposomes were investigated using TLC at 25, 40 and $55^{\circ} \mathrm{C}$. First, ${ }^{64} \mathrm{CuCl}_{2}$ was dissolved in buffer $(10 \mathrm{mM}$ HEPES, $150 \mathrm{mM} \mathrm{NaCl}, \mathrm{pH}$ 7.4) at $200 \mathrm{MBq} / \mathrm{mL}$. Secondly, $100 \mu \mathrm{L} 9.4 \mathrm{mM}$ liposomes were equilibrated at the target temperature $\left(25,40\right.$ or $\left.55^{\circ} \mathrm{C}\right)$ in an acid washed HPLC vial with constant stirring. The experiments were initiated by adding $100 \mu \mathrm{L}^{64} \mathrm{Cu}^{2+}$ solution (equilibrated at the target temperature) and TLC spots were deposited after 1, 3, 8, 15, 30 and $60 \mathrm{~min}$. The TLC plate was subsequently developed as described above. 


\subsection{X-ray absorption spectroscopy of non-radioactive Cu-loaded liposomes}

Liposomes were prepared from HSPC:CHOL:DSPE-PEG ${ }_{2000}$ (56.5:38.2:5.3), by hydration of lipid powder in a solution of $10 \mathrm{mM}$ HEPES and $100 \mathrm{mM}$ DOTA $(\mathrm{pH} 7.4,325 \mathrm{mOsm} / \mathrm{kg})$. These liposomes were prepared with a higher copper loading capacity using $100 \mathrm{mM}$ DOTA, and were extruded and purified as described in section 2.3.

The liposomes were loaded with non-radioative copper $(\mathrm{Cu})$ by mixing with $\mathrm{CuCl}_{2}$ dissolved in aqueous buffer (10 HEPES mM, $150 \mathrm{mM} \mathrm{NaCl}$, pH 7.4). First, $400 \mu \mathrm{L}$ liposomes (entrapping $100 \mathrm{mM}$ DOTA) were mixed with $66 \mu \mathrm{L}$ of a $\mathrm{CuCl}_{2}$ solution $(6.2 \mathrm{mM})$. Secondly, the liposome-copper mixture was incubated in a closed vial at $55^{\circ} \mathrm{C}$ for $2 \mathrm{~h}$, and the sample was shaken gently regularly. Finally, the sample was equilibrated at room temperature.

The loading efficiency was measured by ICP-MS (Thermo Scientific, iCAP Q). This was accomplished by mixing $10 \mu \mathrm{L} \mathrm{Cu}$-loaded liposome sample with $40 \mu \mathrm{L}$ EDTA $(1 \mathrm{mM})$ (dissolved in HEPES buffer, $\mathrm{pH}$ adjusted to 7.4) and $950 \mu \mathrm{L}$ HEPES buffer. The sample was incubated at room temperature for $15 \mathrm{~min}$, and the total $\mathrm{Cu}$ content of the EDTA spiked sample was determined by a 100fold dilution of the sample in $3 \% \mathrm{HNO}_{3}$ solution (spiked with $25 \mathrm{ppb} \mathrm{Ga}$ as internal standard). The $\mathrm{Cu}$ content of the liposome exterior was determined via spin filtration of the EDTA spiked sample. Briefly, $950 \mu \mathrm{L}$ EDTA spiked sample were transferred to an Amicon Ultra-15 centrifugal filter unit (100 kDa cutoff), which was spun at $1000 \mathrm{~g}$ for $15 \mathrm{~min}$, or until $250 \mu \mathrm{L}$ had passed the filter. Following, filtrate was diluted 100 fold with $3 \% \mathrm{HNO}_{3}$ solution (spiked with $25 \mathrm{ppb} \mathrm{Ga}$ as internal standard). The copper content of the unfiltered sample and sample filtrate were quantified by ICP-MS, and the loading efficiency was calculated as the ratio of filtrate and total copper content. The recovery of copper for the spin filtration method was tested by conducting loading experiments with either no or empty liposomes not entrapping any chelator using matching conditions as for loading of the DOTA-liposomes.

Copper K-edge X-ray absorption spectra were recorded for solvated $\mathrm{Cu}\left(790 \mu \mathrm{M} \mathrm{CuCl}_{2}\right.$ in 10 mM HEPES, $150 \mathrm{mM} \mathrm{NaCl}, \mathrm{pH}$ 7.4), Cu-DOTA (790 $\mu \mathrm{M} \mathrm{CuCl}_{2}, 1.0 \mathrm{mM}$ DOTA in $10 \mathrm{mM}$ HEPES, 150 
$\mathrm{mM} \mathrm{NaCl}, \mathrm{pH} 7.4)$, and $\mathrm{Cu}$-loaded liposomes $\left(720 \mu \mathrm{M} \mathrm{CuCl}_{2}\right)$ on beamline $\mathrm{I} 811$ at the MAX-II synchrotron at MAXIV Laboratory, Lund, Sweden, ${ }^{19}$ using a Si(111) double-crystal monochromator. The samples were mounted in $1 \mathrm{~mm}$ thick sample holders ${ }^{20}$ and cooled to $20 \mathrm{~K}$ in a liquid helium cryostat. Fluorescence data were collected using a Vortex silicon-drift detector $\left(50 \mathrm{~mm}^{2}\right)$ in the XANES region 8830-9180 eV. Five to ten scans of 25 min were recorded for each sample in following intervals: Preedge data (150-20 eV before the edge) were collected in steps of $5 \mathrm{eV}$ for $1 \mathrm{sec}$, the edge (from $20 \mathrm{eV}$ before to $30 \mathrm{eV}$ above the edge) in steps of $0.3 \mathrm{eV}$ for $1 \mathrm{sec}$, the XANES region (30-120 eV above the edge) in steps of $1 \mathrm{eV}$ for $1 \mathrm{sec}$, and the NEXAFS region (120-200 eV above the edge) in steps of $5 \mathrm{eV}$ for $3 \mathrm{sec}$. Comparing successive scans, no photo reduction or radiation damage of the samples were observed.

The scans were, averaged, background subtracted, normalized and energy calibrated using WinXAS. ${ }^{21}$ Full multiple scattering calculations of XANES spectra by finite-difference methods (FDM) were performed using FDMNES, ${ }^{22}$ on clusters with a radius of $4.5 \AA$ of the $\mathrm{Cu}$-atom. The fit between calculated and experimental spectra was evaluated with an $\mathrm{R}$ factor given as:

$R_{\text {xanes }}=\frac{\sum\left|\mu^{\exp }(E)-\mu^{c a l}(E)\right|}{\sum\left|\mu^{\exp }(E)\right|}$

where $\mu$ is the absorption/fluorescence yield from normalized XANES spectra as function of energy, E.

\subsection{Animal xenograft model}

Human FaDu head and neck cancer cells $\left(5 \times 10^{6}\right.$ cells in $100 \mu \mathrm{L}$ media and matrigel $)$ were inoculated subcutaneously in the flanks of female NMRI nude mice $(n=5)$ and were allowed to grow 14 days (tumor sizes $<0.5 \mathrm{~g}$ ). All nude mice were purchased from Taconic (Borup, Denmark), and all experimental procedures were conducted with the guidelines set forth by the Danish Ministry of Justice. ${ }^{64} \mathrm{Cu}$-liposome suspensions were intravenously injected (i.v.) for PET imaging. All animals were anesthetized with sevofluran and catheterized to ensure proper tail vein injection. The average 
administered lipid dose level of ${ }^{64} \mathrm{Cu}$-liposomes was $20 \mathrm{mg} / \mathrm{kg}$. The approximate activity dose level was $12 \mathrm{MBq} /$ animal. PET data were acquired on a MicroPET $^{\circledR}$ Focus 120 (Siemens Medical Solutions, Malvern, PA, USA). The voxel size was $0.866 \times 0.866 \times 0.796 \mathrm{~mm}^{3}$ and in the centre field of view the resolution was $1.4 \mathrm{~mm}$ full width at half maximum (FWHM). PET scans were acquired 5 min after injection of radiolabeled liposomes (scan time $5 \mathrm{~min}$ ) and again $24 \mathrm{~h}$ after injection (scan time $15 \mathrm{~min}$ ). Data were reconstructed with the maximum a posterior (MAP) reconstruction algorithm. For anatomical localization of activity, CT images were acquired with a MicroCAT ${ }^{\circledR}$ II system (Siemens Medical solutions, Malvern, PA, USA).

After data reconstruction, PET- and CT images were fused using the Inveon Software (Siemens). The emission scans were corrected for random counts and dead time. The PET- and CT images were used to identify regions of tracer uptake and to generate regions of interest (ROIs) that were applied to each scan separately. The blood activity was estimated from a spherical ROI constructed within the left heart ventricle. This ROI was subsequently segmented into a blood activity ROI consisting only of voxels displaying minimum $80 \%$ of maximum voxel activity of the original ROI. Liposomal activity within each organ was determined from ROIs placed within the border of the investigated organs. ROIs were placed to ensure sufficient organ coverage without compromising the influence of partial volume effects or respiratory movements. The liposomal accumulation in the different organs was expressed as percentage of injected dose per gram $(\% I D / g)$ as well as standardized uptake value (SUV) ${ }^{23}$ The organ density was assumed to be $1 \mathrm{~g} / \mathrm{cm}^{3}$ for all tissues and tumors.

\subsection{Biodistribution and circulation properties in a clinical canine model}

A large breed dog (Great Dane, male, $48 \mathrm{~kg}$ ) underwent ${ }^{64} \mathrm{Cu}$-liposome PET/CT scanning following a previous surgical removal of a neuroblastoma to evaluate presence of metastatic or residual cancerous tissue. The study was approved by the Ethical Committee at Dept. Small Animal Clinical Sciences at University of Copenhagen in Denmark. The dog was injected with $2 \mathrm{mg} / \mathrm{kg}$ of dexamethasone disodium 
phosphate approx. $2 \mathrm{~h}$ prior to infusion of ${ }^{64} \mathrm{Cu}$-liposomes to minimize risks of immunologic reactions. ${ }^{64} \mathrm{Cu}$-liposomes were infused over a 20 -min period at increasing infusion rates, a total of $402.7 \mathrm{MBq}$ of ${ }^{64} \mathrm{Cu}$-liposomes was infused, equalling a mean lipid concentration of $4.3 \mathrm{mg} / \mathrm{kg}$. EDTA stabilized blood samples were collected at multiple time points during a 24-hour period. Blood samples were weighed and well-counted in triplicates and specific decay corrected injected activity was determined from an expected blood volume ( $8 \%$ of bodyweight).

After a distribution period of 24-hours the dog was anesthetized and a whole body PET/CT scan performed to evaluate biodistribution of the ${ }^{64} \mathrm{Cu}$-liposomes and presence of detectable metastatic or residual disease. PET/CT scans were performed using a combined PET/CT scanner (Biograph 40 PET/CT) consisting of a high resolution PET scanner (21.6 cm axial field) and a 40-row multi-slice CT scanner. Images were reconstructed using a 3D acquisition mode and attenuation corrected using the concurrent CT scan. PET images were acquired using 2.5 min per bed positions and reconstructed using TrueX $^{\circledR}$ (Siemens, Erlangen, Germany) 3D reconstruction (21 iterations, 3 subsets), and smoothed using a Gaussian filter having a FWHM of $2 \mathrm{~mm}$ in all directions, and a matrix size of $336 \times 336$.

Image analysis of attenuation corrected and reconstructed PET/CT images were performed using commercial software (Pmod, Pmod Technologies, Switzerland). The acquired images revealed no signs of residual or metastatic cancerous tissue. ${ }^{64} \mathrm{Cu}$-liposome activity in the blood, liver, spleen and muscle $24 \mathrm{~h}$ after ${ }^{64} \mathrm{Cu}$-liposome infusion were evaluated by constructing reference ROIs using the methodology described above and reported as \% ID/g. All regions were drawn well within the margins of tissues and organs, and excluding regions containing larger blood vessels, e.g. the hilar region of the liver, to avoid artefacts and minimize partial volume effects and respiratory movement.

\subsection{In vitro stability of ${ }^{64} \mathrm{Cu}$-liposomes in serum}


In vitro stability of ${ }^{64} \mathrm{Cu}$-liposomes, prepared by the $\mathrm{UAL}$ method, was tested in human serum, canine and mice plasma. Liposomes loaded with $500 \mathrm{MBq}{ }^{64} \mathrm{Cu} / \mathrm{mL}$ were mixed with serum or plasma in a 1:1 ratio, and incubated for $18 \mathrm{~h}$ at $37^{\circ} \mathrm{C}$. The liposome-serum/plasma mixture $(200 \mu \mathrm{L})$ was separated on a sizeexclusion column (Sephadex G50 fine, $25 \times 1.5 \mathrm{~cm}$, flow rate $1 \mathrm{~mL} / \mathrm{min}$ ) and fractions were collected every $2^{\text {nd }} \mathrm{min}$. The ${ }^{64} \mathrm{Cu}$ activity of the different fractions was measured using a calibrated high-purity germanium detector (Princeton, Gammatech). Each sample was placed in a distance of $20 \mathrm{~cm}$ measured from the surface of the detector crystal. Energy and efficiency calibrations were performed prior to measuring using certified sealed radioactive sources of ${ }^{133} \mathrm{Ba}$ and ${ }^{152} \mathrm{Eu}$. The spectra were obtained and analyzed using Canberra Genie2K software. The ${ }^{64} \mathrm{Cu}$ activity of each sample was determined by integration of the $511 \mathrm{keV}$ annihilation peak and the activities were calculated based on the $20 \mathrm{~cm}$ efficiency calibration. ${ }^{64} \mathrm{Cu}$-DOTA was included as a control to determine retention-time (fraction range) of the liposome encapsulated and free ${ }^{64} \mathrm{Cu}$-DOTA. The leakage of ${ }^{64} \mathrm{Cu}$-DOTA from the liposomes in serum or plasma was calculated as leakage $=\sum_{i=13}^{25} A_{\text {frac }}^{i} / \sum_{i=1}^{25} A_{\text {frac }}^{i}$, where $A_{\text {frac }}^{i}$ is the activity of the i'th fraction (see supplementary Figure S1).

\section{Results}

\subsection{Loading of ${ }^{64} \mathrm{Cu}^{2+}$ evaluated by SEC}

In the present work, loading of ${ }^{64} \mathrm{Cu}^{2+}$ into DSPC:CHOL:DSPE-PEG 2000 (50:40:10) liposomes was tested using an UAL and an IAL method, which are schematically illustrated in Figure 1. The two loading methods are compared by the overall loading efficiency $\left(\%\right.$ load $\left._{s e c}\right)$ determined using SEC (Figure 2A), which for IAL using 2HQ (Figure 2B) shows an increase from $83 \%$ to $92 \%$ (11\% relative increase) in response to raising the temperature from $30^{\circ} \mathrm{C}$ to $50^{\circ} \mathrm{C}$. In contrast, the $\mathrm{UAL}$ method (without $2 \mathrm{HQ}$ ) shows an increase from $47 \%$ to $97 \%$ ( $>100 \%$ relative increase) in response to raising the temperature from $30^{\circ} \mathrm{C}$ to $50^{\circ} \mathrm{C}$ (Figure $\left.2 \mathrm{~B}\right)$. 

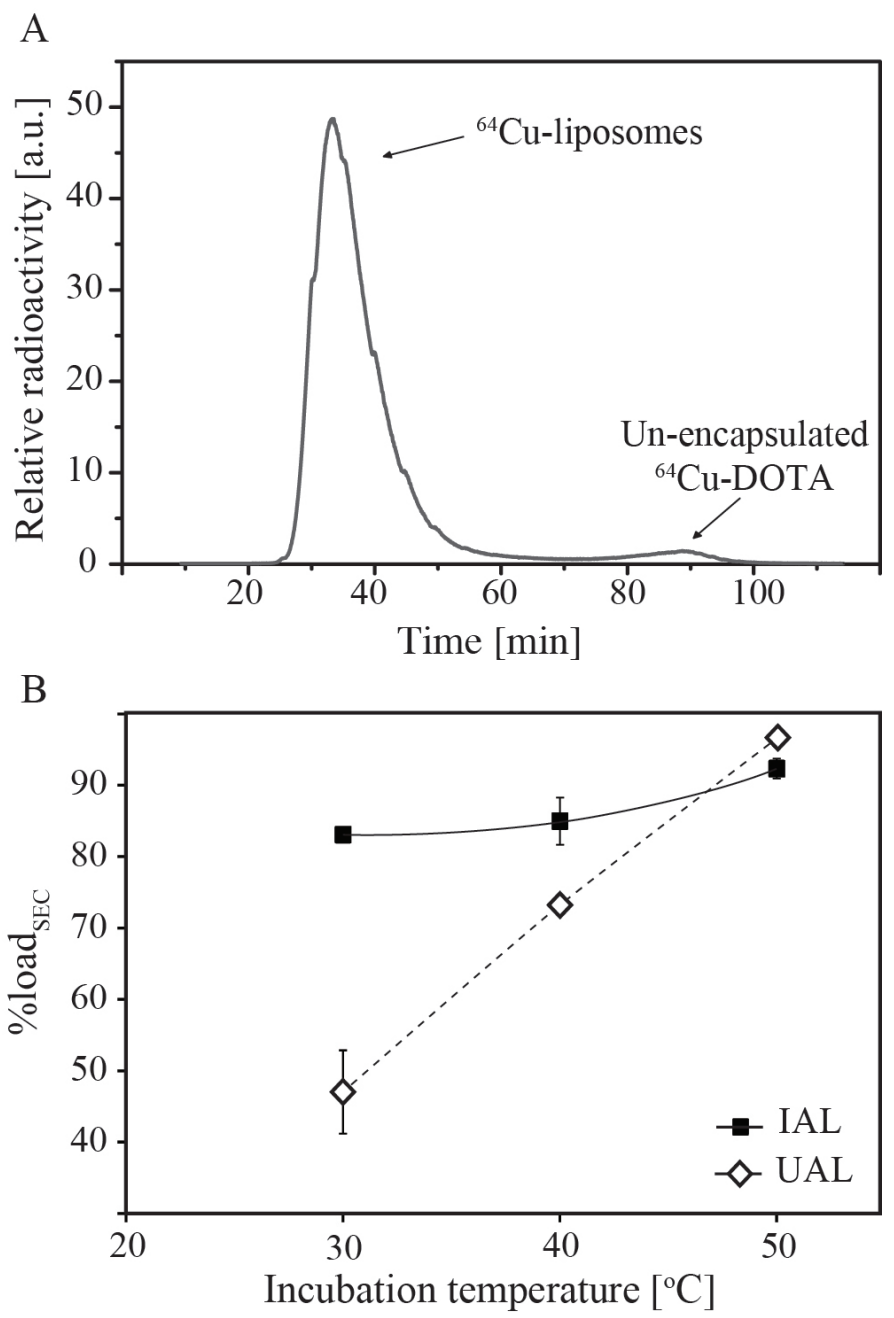

Figure 2. Evaluation of ${ }^{64} \mathrm{Cu}^{2+}$ loading into DOTA-liposomes using size exclusion chromatomography (SEC). (A) A typical SEC elution profile of ${ }^{64} \mathrm{Cu}^{2+}$ remote loaded liposomes (B) Loading efficiency presented as a function of temperature for the unassisted (UAL) and ionophore assisted (IAL) remote loading. The liposomes were composed of DSPC:CHOL:DSPE-PEG 2000 in the molar ratio (50:40:10) with the chelator (DOTA) entrapped. The error bars represent SEM $(n=3)$.

The largest difference in loading efficiency, between the two loading methods, is observed at $30^{\circ} \mathrm{C}$ and $40^{\circ} \mathrm{C}$. Furthermore, $2 \mathrm{HQ}$ is observed to reduce the maximal achieved loading from $97 \% \pm 1 \%$ to $92 \% \pm$ 1\%. As control, loading of empty liposomes (without DOTA encapsulated) was carried out using the method described above and showed loading efficiencies of $1 \% \pm 1 \%$ and $5 \% \pm 1 \%$ for $5 \mathrm{mM}$ and $50 \mathrm{mM}$ DSPC:CHOL:DSPE-PEG 2000 (50:40:10) lipid formulations, respectively, when incubated for $1 \mathrm{~h}$ at $55^{\circ} \mathrm{C}$. 


\subsection{Loading kinetics of ${ }^{64} \mathrm{Cu}^{2+}$ evaluated by radio- $T L C$}

The kinetics of loading ${ }^{64} \mathrm{Cu}^{2+}$ into liposomes, utilizing the new UAL method, was evaluated using radioTLC (Figure 3A). Loading experiments were conducted at 25, 40 and $55^{\circ} \mathrm{C}$, using HSPC:CHOL:DSPE$\mathrm{PEG}_{2000}(56.5: 38.2: 5.3)$ liposomes (Figure 3B).
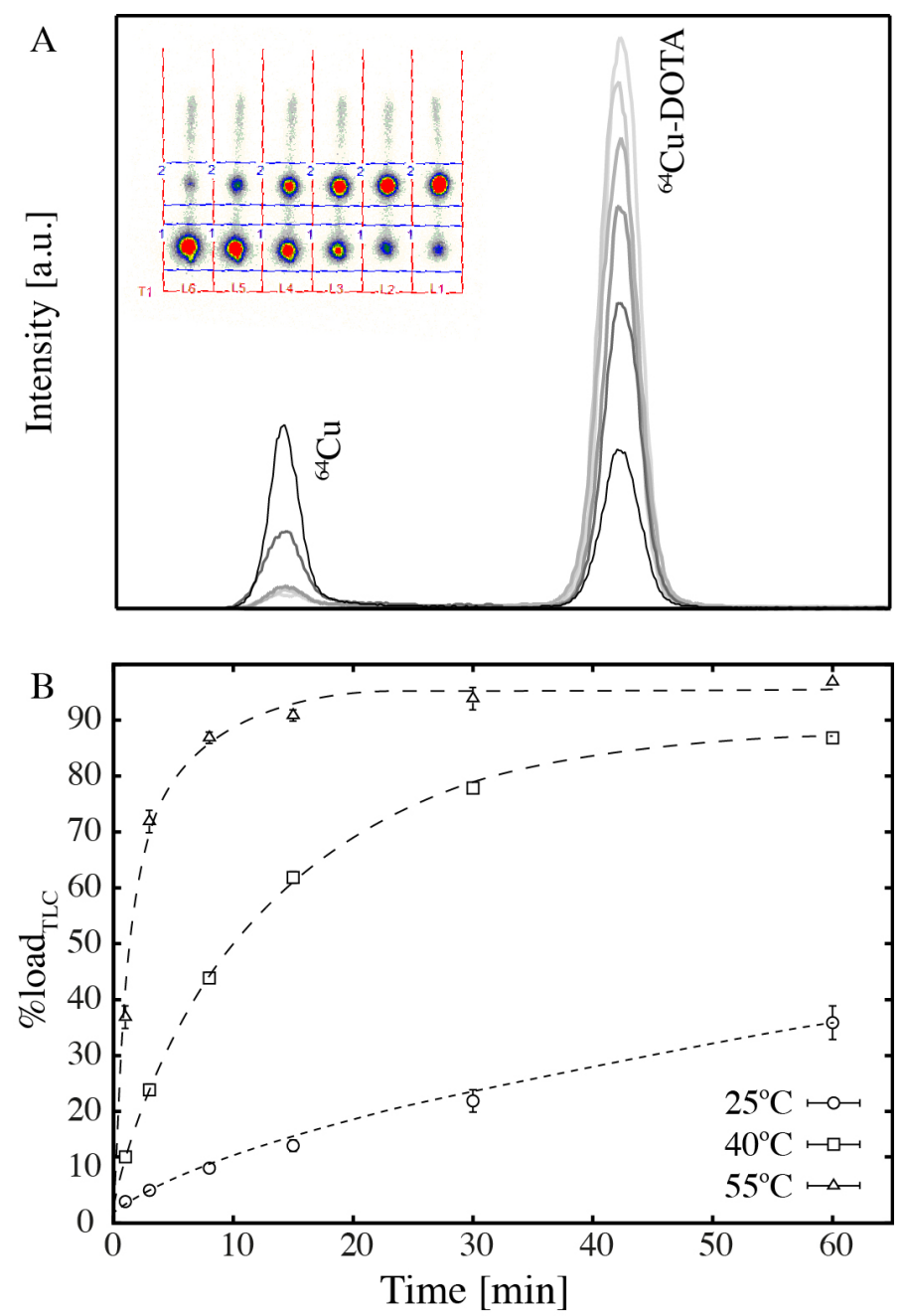

Figure 3. Loading efficiency of liposomes given as function of time for the UAL method. The loading efficiency, for loading of ${ }^{64} \mathrm{Cu}^{2+}$ into liposomes, is evaluated at 25,40 and $55^{\circ} \mathrm{C}$ by the use of radio-TLC. (A) TLC elution profile as function of time $(1,3,8,15,30$ and $60 \mathrm{~min})$. The corresponding TLC plate is shown as an insert in panel A. (B) Degree of loading ${ }^{64} \mathrm{Cu}^{2+}$ into liposomes (\%load TLC $_{\text {). The liposomes }}$ were composed of HSPC:CHOL:DSPE-PEG ${ }_{2000}$ in the molar ratio (56.5:38.2:5.3). The error bars represent SEM $(n=3)$. 
Slow loading kinetics is observed at room temperature $\left(25^{\circ} \mathrm{C}\right)$, where a maximal loading efficiency of $36 \% \pm 4 \%$ is reached after $60 \mathrm{~min}$. At $40^{\circ} \mathrm{C}$, loading kinetics is faster, and a maximal loading efficiency of $88 \% \pm 1 \%$ is reached after $60 \mathrm{~min}$. The fastest loading is observed at $55^{\circ} \mathrm{C}$, where $97 \% \pm 1 \%$ loading is reached after $60 \mathrm{~min}$. The initial velocity of the ${ }^{64} \mathrm{Cu}^{2+}$ loading reaction, judged by the degree of loading achieved after $1 \mathrm{~min}$, increases from $5 \% \pm 1 \%$ at $25^{\circ} \mathrm{C}$ to $12 \% \pm 1 \%$ at $40^{\circ} \mathrm{C}$, and reaches $38 \% \pm 3 \%$ at $55^{\circ} \mathrm{C}$. A temperature increase of $30^{\circ} \mathrm{C}$ thus results in a 8 -fold increase in initial loading rate.

\subsection{Remote loading of non-radioactive $C u$ and $X$-ray absorption spectroscopy analysis}

The coordination chemistry of copper was investigated using X-ray absorption spectroscopy (XAS) in order to elucidate copper species present in HEPES buffer, HEPES buffer containing DOTA and in remote loaded liposomes prepared using the UAL method. Therefore, HSPC:CHOL:DSPE-PEG ${ }_{2000}$ (56.5:38.2:5.3) liposomes, entrapping $100 \mathrm{mM}$ DOTA, was mixed with non-radioactive copper $(\mathrm{Cu})$. Sample incubation was conducted at $55^{\circ} \mathrm{C}$ for an extended period of time $(2 \mathrm{~h})$ to facilitate loading of the larger amount of copper, compared to loading of ${ }^{64} \mathrm{Cu}^{2+}$. The liposome sample was examined using ICPMS, which resulted in a total copper content of $720 \mu \mathrm{M}$ and an encapsulation efficiency of $93 \%$. Loading of HSPC:CHOL:DSPE-PEG 2000 (56.5:38.2:5.3) liposomes, entrapping no chelator, resulted in 5\% loading. The recovery of copper from the spin filters has furthermore been analyzed by conducting a test loading without any liposomes. This test shows that upon complex formation of copper and EDTA, more than $96 \%$ of the copper in the sample is recovered in the filtrate. Solutions containing $720 \mu \mathrm{M}$ copper (in HEPES buffer) or $720 \mu \mathrm{M}$ copper and $1.0 \mathrm{mM}$ DOTA (in HEPES buffer) was prepared. Together, these solutions and a sample of $\mathrm{Cu}$-loaded liposomes were investigated using XAS.

$X$-ray absorption spectroscopy: The experimental and calculated XANES spectra of solvated $\mathrm{Cu}$ in HEPES buffer, $\mathrm{Cu}$-DOTA and $\mathrm{Cu}$-loaded liposomes are shown in Figure 4A. The XANES spectra confirm the presence of copper in oxidation state $+2\left(\mathrm{Cu}^{2+}\right)$ in all samples as seen by the absence of the 
characteristic pre-edge feature around $8983 \mathrm{eV}$ occurring in the XANES spectra of copper in oxidation state $+1 .^{24}$

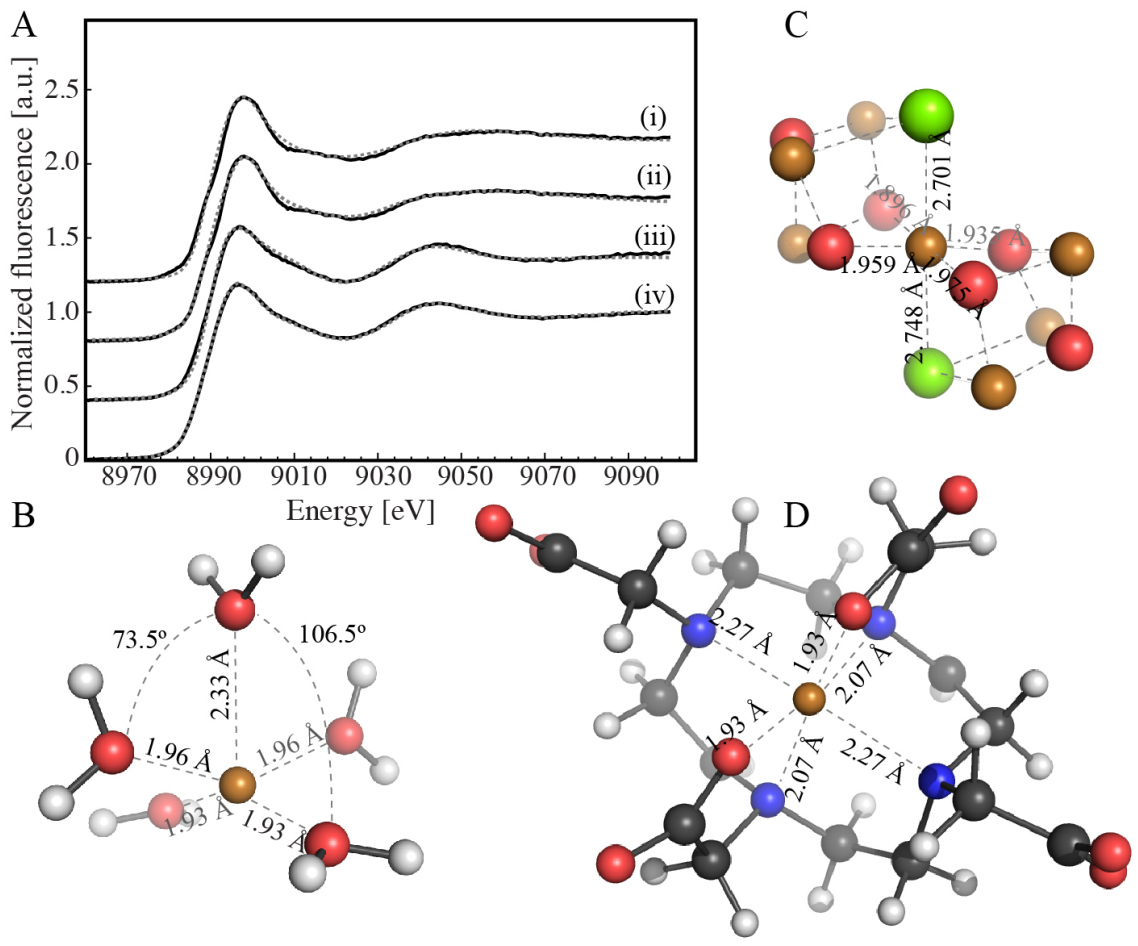

Figure 4. Experimental (solid line) and calculated (dashed) XANES spectra (panel A). From top: (i) Solvated $\mathrm{Cu}^{2+}$ fitted with a five-coordinate water complex, (ii) solvated $\mathrm{Cu}^{2+}$ fitted with clinoatacaite, (iii) $\mathrm{Cu}$-DOTA fitted with $\mathrm{Cu}$-DOTA complex, and (iv) copper loaded liposome fitted with a linear combination of experimental spectra of Cu-DOTA and solvated $\mathrm{Cu}^{2+}$. (B-D) The atomic models used in the calculations of XANES spectra including distances to atoms in the first coordination shell. Panel B show $\left[\mathrm{Cu}\left(\mathrm{H}_{2} \mathrm{O}\right)_{5}\right]^{2+}$ used to model the solvated $\mathrm{Cu}^{2+}$ in HEPES. (C) The most abundant $\mathrm{Cu}$ coordination in clinoatacamite, which was also used to model the solvated $\mathrm{Cu}^{2+}$ in HEPES. The $\left[\mathrm{Cu}(\mathrm{OH})_{4} \mathrm{Cl}\right]^{4-}$ complex is shown with the nearest neighbour copper atoms. (D) Cu-DOTA complex. Colour code: copper (brown), chlorine (green), oxygen (red), nitrogen (blue), carbon (black) and hydrogen (white).

XANES spectra were calculated from different models in order to identify the ${ }^{63} \mathrm{Cu}^{2+}$-species present in the HEPES buffer sample. Firstly, XANES spectra were calculated for different complexes in which $\mathrm{Cu}^{2+}$ is solely ligated by water in the following geometries: $i$ ) Jahn-Teller distorted six-coordinate $\left[\mathrm{Cu}\left(\mathrm{H}_{2} \mathrm{O}\right)_{6}\right]^{2+}$, ii) regular five-coordinate square pyramidal $\left[\mathrm{Cu}\left(\mathrm{H}_{2} \mathrm{O}\right)_{5}\right]^{2+}$ and iii) elongated five-coordinate square pyramidal $\left[\mathrm{Cu}\left(\mathrm{H}_{2} \mathrm{O}\right)_{5}\right]^{2+}$ in which the four equatorial ligands were $D_{2 d}$-distorted from the mean 
equatorial plane as shown in Figure 4B. This latter model shown in Figure 4B was adapted from the XAS solution structure of $\left[\mathrm{Cu}\left(\mathrm{H}_{2} \mathrm{O}\right)_{5}\right]^{2+}$ at room temperature by Frank et al., ${ }^{25}$ and results in a significantly better agreement with the measured XANES spectrum $\left(R_{\text {xanes }}=0.0217\right)$, as compared to the six-coordinate complex $\left(R_{\text {xanes }}=0.0384\right)$ and the regular five-coordinate square pyramidal complex $\left(R_{\text {xanes }}=0.0284\right)$. A $1.0 \%$ reduction of the $\mathrm{Cu}-\mathrm{O}$ distances due to temperature differences further improved the fit as shown in Figure $4 \mathrm{~A}\left(R_{\text {xanes }}=0.0179\right)$.

After a few days, a precipitate was observed in the buffer sample. An X-ray powder diffraction analysis identified this precipitate as clinoatacamite, which is a monoclinic polymorph of dicopper trihydroxide chloride. ${ }^{26}$ Clinoatacamite contains three crystallographically different copper atoms, of which three quarters of them adopt a six-coordinate Jahn-Teller distorted geometry $\left[\mathrm{Cu}(\mathrm{OH})_{4} \mathrm{Cl}_{2}\right]^{4-}$, similar to that shown in Figure 4C, which is a strong indication of coordination of chloride to copper. A XANES spectrum was therefore calculated from this structure. This resulted in a very good agreement with the measured XANES spectrum, as some of the spectral features are better explained by this model compared to the $\mathrm{Cu}$-aqua models. This includes improved fit of the subtle edge feature at $8990 \mathrm{eV}$ as well as the shoulder around $9013 \mathrm{eV}$ (Figure 4A). As the crystal structure was solved at room temperature shorter coordination distances were observed in the experimental XANES spectrum, and therefore an isotropic contraction of the unit cell of $2.0 \%$ was applied to optimize the fit $\left(R_{\text {xanes }}=0.0145\right)$. The orthorhombic crystal structure of the Cu-DOTA, ${ }^{27}$ which is shown in Figure $4 \mathrm{D}$ was used to calculate the XANES spectrum of the Cu-DOTA complex. The fit was further improved by a $1.9 \%$ isotropic contraction of the unit cell in which $R_{\text {xanes }}$ improved from 0.0214 to 0.0149 .

A linear combination of the experimental spectra of solvated $\mathrm{Cu}^{2+}$ and $\mathrm{Cu}$-DOTA, was fitted to the experimental XANES spectrum of Cu-loaded liposome $\left(R_{\text {xanes }}=0.0064\right)$. The fit is shown in Figure 4A. The fraction of copper coordinated to DOTA was refined to $88 \%$, which is in agreement with the loading of $93 \%$. This concludes that $\mathrm{Cu}^{2+}$ is loaded into the liposomes, where it is chelated by DOTA. 


\subsection{Dependence on lipid composition and activity}

The new UAL method was tested for an extended set of liposome formulations listed in Table 1 and all were successfully loaded $\left(\% \operatorname{load}_{\mathrm{SEC}}>95 \%, \% \operatorname{load}_{\mathrm{TLC}}>95 \%\right)$. The loading efficiency, evaluated by SEC and radio-TLC, is found to be independent of: 1) DSPE-PEG ${ }_{2000}$ content for the stealth formulation, 2)

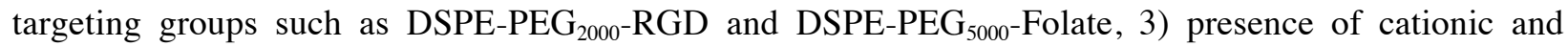
anionic lipids, 4) cholesterol content and 5) lipid saturation or membrane phase-state (gel or fluid). Moreover, stealth liposomes were successfully loaded at low, medium and high radioactivity levels (10$\left.800 \mathrm{MBq} / \mathrm{mL}^{64} \mathrm{Cu}^{2+}\right)$.

Table 1. Liposomal formulations and loading conditions for which successful unassisted loading (UAL) of ${ }^{64} \mathrm{Cu}^{2+}$ has been achieved $\left(\% \operatorname{load}_{\mathrm{SEC}}>95 \%\right.$, \%load $\left.{ }_{\mathrm{TLC}}>95 \%\right)$. Loading conditions are specified as: loading temperature, lipid concentration and ${ }^{64} \mathrm{Cu}$ activity.

\begin{tabular}{|c|c|}
\hline Liposomal formulations (molar ratio) & Loading conditions \\
\hline \multicolumn{2}{|l|}{ Stealth liposomes } \\
\hline $\begin{array}{l}\text { HSPC:CHOL:DSPE-PEG } \\
2000 \\
\text { DSPC:CHOL:DSPE-PEG } \\
2000 \\
(50: 4: 30: 10)\end{array}$ & $\begin{array}{l}55^{\circ} \mathrm{C}, 3.3-10 \mathrm{mM}, 10-800 \mathrm{MBq} / \mathrm{mL} \\
55^{\circ} \mathrm{C}, 3.3-10 \mathrm{mM}, 50-100 \mathrm{MBq} / \mathrm{mL}\end{array}$ \\
\hline \multicolumn{2}{|l|}{ Targeted stealth liposomes } \\
\hline $\begin{array}{l}\text { DSPC:CHOL:DSPE-PEG } \\
\text { (55:40:4:1) } \\
\text { DSPC:CHOL:DSPE-PEG } \\
\text { DS000: }: \text { DSPE-PEG }_{2000}-\text { RGD } \\
(56.2: 38.0: 5.3: 0.5)\end{array}$ & $\begin{array}{l}55^{\circ} \mathrm{C}, 3.3 \mathrm{mM}, 50-200 \mathrm{MBq} / \mathrm{mL} \\
55^{\circ} \mathrm{C}, 3.3 \mathrm{mM}, 50-200 \mathrm{MBq} / \mathrm{mL}\end{array}$ \\
\hline \multicolumn{2}{|l|}{ Cationic and anionic liposomes } \\
\hline 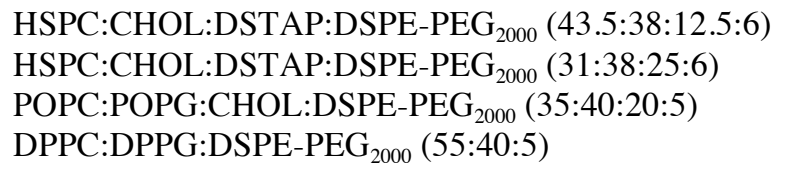 & $\begin{array}{l}55^{\circ} \mathrm{C}, 3.3 \mathrm{mM}, 50-200 \mathrm{MBq} / \mathrm{mL} \\
55^{\circ} \mathrm{C}, 3.3 \mathrm{mM}, 50-200 \mathrm{MBq} / \mathrm{mL} \\
55^{\circ} \mathrm{C}, 5 \mathrm{mM}, 50-200 \mathrm{MBq} / \mathrm{mL} \\
55^{\circ} \mathrm{C}, 5 \mathrm{mM}, 50-200 \mathrm{MBq} / \mathrm{mL}\end{array}$ \\
\hline \multicolumn{2}{|l|}{ Zwitterionic liposomes } \\
\hline $\begin{array}{l}\text { POPC }(100) \\
\text { POPC:CHOL (60:40) } \\
\text { DPPC (100) } \\
\text { DSPC:CHOL (60:40) }\end{array}$ & $\begin{array}{l}40,55^{\circ} \mathrm{C}, 5 \mathrm{mM}, 50-200 \mathrm{MBq} / \mathrm{mL} \\
55^{\circ} \mathrm{C}, 5 \mathrm{mM}, 50-200 \mathrm{MBq} / \mathrm{mL} \\
55^{\circ} \mathrm{C}, 3.3 \mathrm{mM}, 50-200 \mathrm{MBq} / \mathrm{mL} \\
55^{\circ} \mathrm{C}, 3.3 \mathrm{mM}, 50-200 \mathrm{MBq} / \mathrm{mL}\end{array}$ \\
\hline
\end{tabular}




\subsection{In vivo and in vitro performance of ${ }^{64} \mathrm{Cu}$-liposomes}

The in vivo performance of ${ }^{64} \mathrm{Cu}^{2+}$ loaded HSPC:CHOL:DSPE-PEG ${ }_{2000}$ (56.5:38.2:5.3) liposomes (prepared by the UAL method) was investigated in a xenograft FaDu tumor model. Each animal was injected in the tail vein with $200 \mu \mathrm{L}$ liposome formulation (3.3 mM lipid, $60 \mathrm{MBq} / \mathrm{mL}$ ) corresponding to $20 \mathrm{mg} \mathrm{lipid} / \mathrm{kg}$ and an activity dose level of $12 \mathrm{MBq} / \mathrm{animal}$. The mice were PET/CT scanned $10 \mathrm{~min}$ and $24 \mathrm{~h}$ post injection, as shown in the PET/CT fusion images of Figure 5A-D.

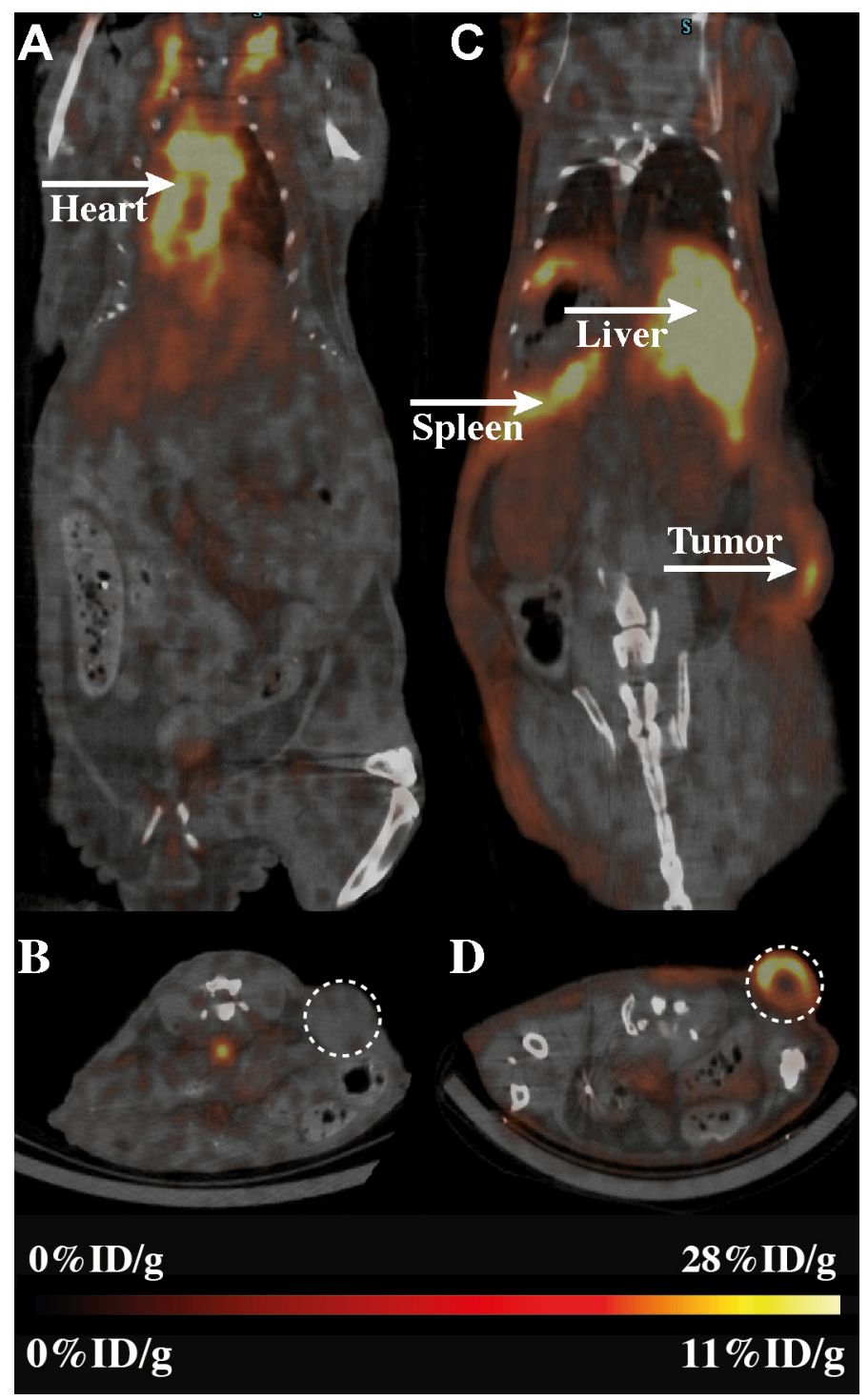

Figure 5. Coronal PET/CT image of FaDu tumor xenografts mice models injected with ${ }^{64} \mathrm{Cu}$-liposomes (prepared using the UAL method). (A-B) Organ and tumor distribution 10 min post injection of ${ }^{64} \mathrm{Cu}-$ liposomes and (C-D) $24 \mathrm{~h}$ post injection. The intensity scale bar presents the uptake in $\% \mathrm{ID} / \mathrm{g}$ and covers 
the range $0-28 \% \mathrm{ID} / \mathrm{g}$ in (A-B) and $0-11 \% \mathrm{ID} / \mathrm{g}$ in (C-D). The liposomes were composed of HSPC:CHOL:DSPE-PEG 2000 in the molar ratio (56.5:38.2:5.3). The dashed circle in (B,D) defines the position of the tumor.

The blood, tumor and organ accumulation, compiled in Table 2, has been quantified using PET imaging. Ten minutes post injection, the ${ }^{64} \mathrm{Cu}$-liposomes reside in the blood pool, which is evident in Figure $5 \mathrm{~A}$ where a high ${ }^{64} \mathrm{Cu}^{2+}$ radioactivity is observed in the region of the heart. Only little activity is observed in the tumor (Figure 5B) at this time point. After $24 \mathrm{~h}$, the ${ }^{64} \mathrm{Cu}$-liposomes accumulate in the spleen, liver and tumor as indicated by high ${ }^{64} \mathrm{Cu}^{2+}$ radioactivity in tissues in Figure $5 \mathrm{C}$ and uptake data in Table 2. The ${ }^{64} \mathrm{Cu}$-liposome content in the blood decreases from $(33 \pm 4) \% \mathrm{ID} / \mathrm{g}$ at $10 \mathrm{~min}$ to $(6.4 \pm 0.4) \% \mathrm{ID} / \mathrm{g}$ at $24 \mathrm{~h}$, which corresponds to a half-life of $\mathrm{T}_{1 / 2}=9.7 \mathrm{~h}$ assuming mono-exponential blood clearance. Assuming an average weight of $27.5 \mathrm{~g}$ and an average blood volume of $8 \% \mathrm{v} / \mathrm{w}, 73 \%$ of the injected dose is accounted for by the blood pool 10 min post injection.

Table 2. Biodistribution data for ${ }^{64} \mathrm{Cu}$-liposomes administered to $\mathrm{FaDu}$ tumor bearing mice $(\mathrm{n}=5)$ and a $\operatorname{dog}(\mathrm{n}=1)$. The liposomes were composed of HSPC:CHOL:DSPE-PEG ${ }_{2000}$ in the molar ratio (56.5:38.2:5.3). Scans were performed $10 \mathrm{~min}$ or $24 \mathrm{~h}$ post injection. Values are means \pm SEM $(n=5)$.

\begin{tabular}{lcccc}
\hline & \multicolumn{2}{c}{ Mice } & \multicolumn{2}{c}{ Dog } \\
\cline { 2 - 5 } Organs & $\% \mathrm{ID} / \mathrm{g}$ & SUV & \%D/kg & SUV \\
\hline Blood (10 min) & $33 \pm 4$ & $10 \pm 1$ & - & - \\
Blood (24 h) & $6.4 \pm 0.4$ & $1.9 \pm 0.1$ & 12.0 & 5.7 \\
Liver (24 h) & $13 \pm 1$ & $3.9 \pm 0.3$ & 7.9 & 3.8 \\
Spleen (24 h) & $14 \pm 2$ & $4.2 \pm 0.6$ & 5.2 & 2.5 \\
Muscle (24 h) & $0.4 \pm 0.1$ & $0.12 \pm 0.03$ & 0.4 & 0.2 \\
Tumor (24 h) & $6 \pm 2$ & $1.8 \pm 0.6$ & - & - \\
\hline
\end{tabular}

${ }^{64} \mathrm{Cu}$-liposomes, prepared by the UAL method, were administered to a single canine cancer model, which in concordance with evaluation of disease status also provided information on the in vivo stability in a 
large animal model. PET/CT fusion images of the canine cancer model are shown in Figure 6 A-B, where the activity is located primarily in the region of the spleen, liver and heart.
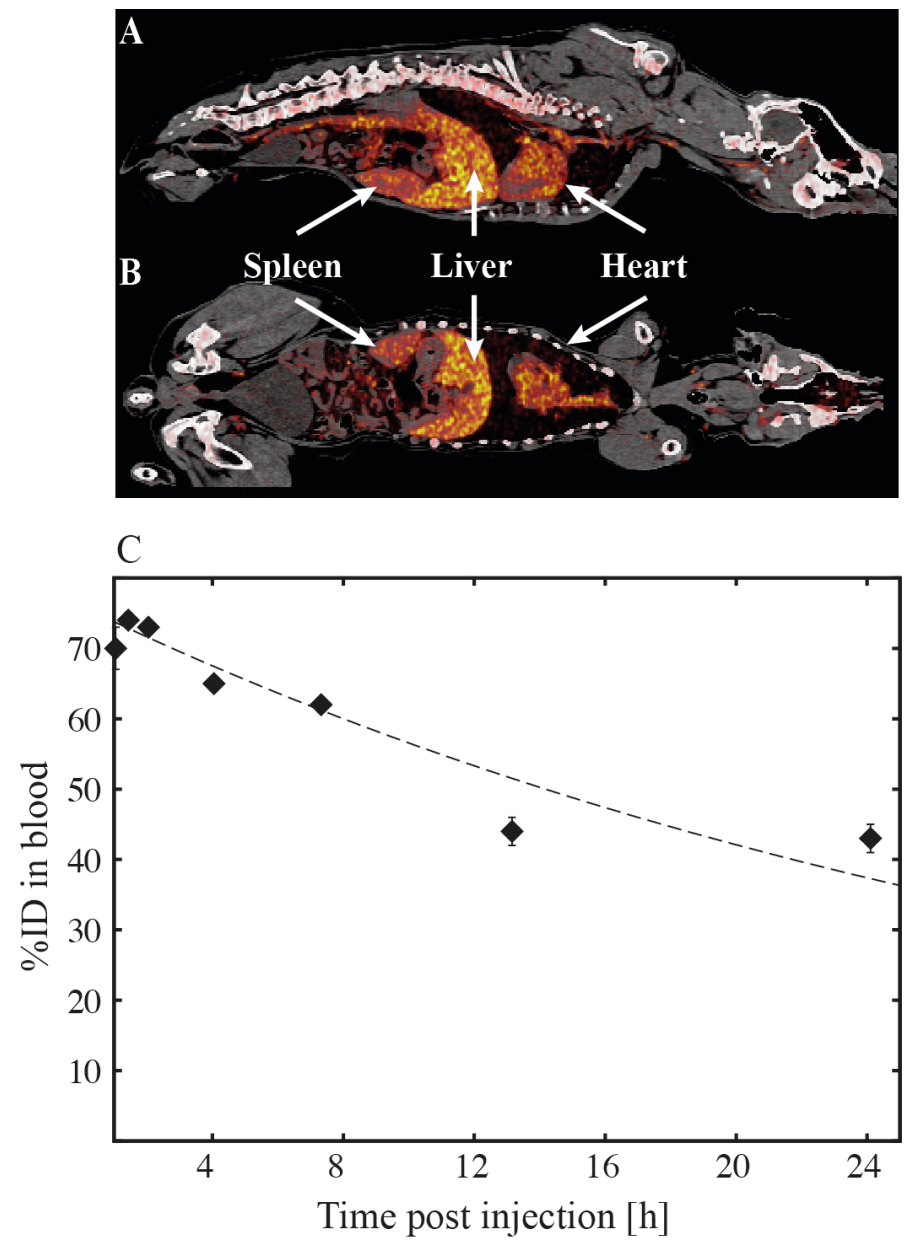

Figure 6. PET/CT image of a canine cancer model injected with ${ }^{64} \mathrm{Cu}$-liposomes (prepared using the UAL method) $24 \mathrm{~h}$ post injection. (A,B) Sagittal and coronal plane PET/CT images are shown with white arrows indicating position of spleen, liver and heart. (C) The blood clearance profile is plotted as function of time post injection of ${ }^{64} \mathrm{Cu}$-liposomes. The dashed line represents the fit of a mono-exponential function. The error bars represent SEM $(n=3)$. The liposomes were composed of HSPC:CHOL:DSPE$\mathrm{PEG}_{2000}$ in the molar ratio (56.5:38.2:5.3).

SUVs and \%ID/kg were quantified by PET imaging and results are reported for tissues and blood in Table 2. The blood clearance profile, shown in Figure 6C, has been fitted using a mono-exponential function, 
which yields a half-life of $\mathrm{T}_{1 / 2}=24 \mathrm{~h} \pm 4 \mathrm{~h}$. The mono-exponential fit (Figure 6C) shows that the blood pool accounts for more than $75 \%$ of the injected dose at the time of injection.

Additionally, the in vitro stability of ${ }^{64} \mathrm{Cu}$-liposomes, prepared by the UAL method, was investigated in human serum, canine and mice plasma (incubated for $18 \mathrm{~h}$ and at $37^{\circ} \mathrm{C}$ ) and was found to be very high with $<5 \%,<3 \%$ and $<2 \%$ leakage of ${ }^{64} \mathrm{Cu}$-DOTA, in three separate experiments.

\section{Discussion}

We have previously presented an efficient method for remote loading of ${ }^{64} \mathrm{Cu}^{2+}$ into liposomes using the ionophore $2 \mathrm{HQ} .{ }^{12}$ In this approach, copper is coordinated by $2 \mathrm{HQ}$ outside the liposomes, which lowers the kinetic energy barrier of crossing the lipid bilayer, and hence facilitates diffusion of the copper complex (Figure 1). Once inside the liposome, $2 \mathrm{HQ}$ is exchanged by entrapped chelators due to the copper affinity and excess chelator concentration. In the current study, a new method, excluding the use $2 \mathrm{HQ}$ or any other ionophore, is presented. In this UAL method, copper is added to liposomes entrapping a chelator, and contrary to previous knowledge, copper spontaneously diffuses across the lipid bilayer where it is captured by the high affinity chelator (DOTA).

The new UAL method has major advantages compared to previous reported IAL methods, ${ }^{4,7-12}$ because of its simplicity, excluding the use of any ionophore. The UAL method only requires an encapsulated chelator and proper incubation temperature to obtain high loading efficiencies (>95\%) of radioactive ${ }^{64} \mathrm{Cu}^{2+}$ into liposomes. High loading efficiency $\left(\% \operatorname{load}_{\mathrm{SEC}}>95 \%, \% \operatorname{load}_{\mathrm{TLC}}>95 \%\right)$ is obtained for a range of ${ }^{64} \mathrm{Cu}^{2+}$ activity levels, lipid concentrations and composition (Table 1) thus highlighting the robustness and flexibility of the new loading method. In particular, loading efficiency is found not to depend on the presence of pegylated lipids, targeting ligands, liposome surface charge, or lipid phase state (gel or fluid). However, changes in surface potential/charge of liposomes are known to affect the spatial distribution of ions near the lipid membrane, ${ }^{28,29}$ which could affect the loading efficiency of $\mathrm{Cu}^{2+}$. Yet, no 
change in loading efficiency is observed for cationic HSPC:CHOL:DSTAP:DSPE-PEG 2000 (31:38:25:6) or anionic POPC:POPG:CHOL:DSPE-PEG ${ }_{2000}$ (35:40:20:5) liposomes (Table 1) indicating that the membrane translocating copper specie might be neutral. In work by Powel et al., speciation of copper in saline solution, in the presence of atmospheric $\mathrm{CO}_{2}$ pressure, revealed $\mathrm{CuCO}_{3}(\mathrm{aq})$ to be the predominant form of copper at $\mathrm{pH} 7.4 .^{30}$ Oil/water-partitioning studies of copper, conducted by Blust and coworkers, ${ }^{31}$ furthermore showed a dramatic increase in oil/water-partitioning of copper as $\mathrm{pH}$ was raised from 6.5 to 7.0. The latter result has been attributed to the formation of carbonate compounds by copper speciation. Both observations made by Powel and Blust fit our suggestion that copper is able to translocate the lipid bilayer in a charge independent manner. Our XANES analyses do not support the hypothesis of $\mathrm{CuCO}_{3}$ being the dominant species in HEPES buffer. We see that copper is present either as a distorted fivecoordinate square pyramidal $\left[\mathrm{Cu}\left(\mathrm{H}_{2} \mathrm{O}\right)_{5}\right]^{2+}$ complex (Figure 4B) or adopt a coordination to chloride $\left(\mathrm{Cu}(\mathrm{OH})_{4} \mathrm{Cl}_{2}\right)$ (Figure 4C) similar to that found in clinoatacamite. This difference might be explained by the larger concentration of copper and chloride used in the XAS experiment compared the concentration used in the speciation calculation. ${ }^{30}$ Liposome formulations with melting transition temperature below $55^{\circ} \mathrm{C}$ have furthermore been successfully loaded at $55^{\circ} \mathrm{C}$. This indicates that little or no DOTA is leached from the liposome as a consequence of crossing the gel-fluid transition temperature.

The loading efficiency of the new UAL and the 2HQ IAL method is compared using SEC. The methods are compared at 30,40 and $50^{\circ} \mathrm{C}$, which reveals a large difference in the temperature response of the loading efficiency (Figure 2). For the IAL method, the loading efficiency is found to be weakly dependent on temperature, where as a larger response to changes in temperature is observed for the UAL method. This difference reflects a significant change in activation energy, and hence a change in loading mechanism; an effect that might be attributed to altered transmembrane diffusion rate of the translocating copper specie in the presence of 2HQ. An important observation is the lower loading efficiency obtained at $50^{\circ} \mathrm{C}$ for the IAL method compared to the UAL method. Hence, the presence of $2 \mathrm{HQ}$ results in a free energy penalty of stripping copper from the ionophore, which shifts the loading reaction: $\mathrm{Cu}^{2+}$ 
(unloaded/free) $\Leftrightarrow \mathrm{Cu}^{2+}$ (loaded into liposome), towards the unloaded form. This argument is fully supported by the ligand exchange constant for the exchange of $\mathrm{Cu}^{2+}$ between $2 \mathrm{HQ}$ and DOTA determined in our recent work. ${ }^{12}$

In order to find the optimal loading conditions and elucidate the temperature response of the UAL method, loading kinetics has been investigated by radio-TLC. The loading rate (slope of \%load $\mathrm{TLC}_{\text {) }}$ and efficiency are found to be highly dependent on temperature, and 8-fold increase in initial loading rate is observed in response changing the temperature from $25^{\circ} \mathrm{C}$ to $55^{\circ} \mathrm{C}$ (Figure 3B). This change in initial rate correlates to the observed change in loading efficiency shown in Figure $2 \mathrm{~B}$, and reflects the increased energy barrier for copper to cross the lipid bilayer unassisted. Despite the reduction in loading rate at room temperature, the loading still progresses and reached $36 \%$ after $1 \mathrm{~h}$. At $55^{\circ} \mathrm{C}$ incubation, $92 \%$ loading is obtained within $15 \mathrm{~min}$, and $>97 \%$ loading is achieved within $60 \mathrm{~min}$; hence $55^{\circ} \mathrm{C}$ was chosen as the optimal loading temperature. Furthermore, the obtained loading $\left(\% \operatorname{load}_{\mathrm{TLC}}\right)$ evaluated at $60 \mathrm{~min}$ (Figure 3B) correlates with the loading efficiency obtained by SEC $\left(\% \operatorname{load}_{\mathrm{SEC}}\right)$ shown in Figure $2 \mathrm{~B}$. Loading of ${ }^{64} \mathrm{Cu}^{2+}$ into empty liposomes resulted in highly reduced (or nearly negligible) loading efficiencies for both the IAL and UAL method when compared to liposomes entrapping DOTA. The loading efficiency of empty liposomes furthermore scaled with the lipid concentration, and agrees with the expected entrapped volume of $100 \mathrm{~nm}$ liposomes.

The UAL method has been investigated by XAS to identify copper species, which are likely to be involved in the loading process. Liposomes with a high DOTA content have been prepared and loaded with $720 \mu \mathrm{M} \mathrm{Cu}^{2+}$, which show that even large amount of copper, can be loaded into liposomes using the UAL method. Analysis of XANES spectra (Figure 4A) confirms copper to be present in oxidation state +2 and to be coordinated to DOTA as expected upon loading into liposomes. In a HEPES buffer containing DOTA $(1 \mathrm{mM})$ copper is concluded to be coordinated to DOTA (Figure 4D). A linear combination of the experimental spectra of solvated $\mathrm{Cu}^{2+}$ and $\mathrm{Cu}$-DOTA, has been fitted to the experimental XANES spectrum of copper loaded liposome $\left(R_{\text {xanes }}=0.0064\right.$, fit is shown in Figure 4A). 
From this fit, the fraction of copper coordinated to DOTA is refined to $88 \%$, which is in agreement with the loading efficiency of $93 \%$ obtained by ICP-MS. This concludes that $\mathrm{Cu}^{2+}$ is loaded into the liposomes, where it is chelated by DOTA.

The in vivo performance of liposomes loaded with ${ }^{64} \mathrm{Cu}^{2+}$ using the UAL method has been accessed in small and large animal models. ${ }^{64} \mathrm{Cu}$-liposomes was administered to mice bearing head and neck cancer xenografts, and accumulation in tissues of interest has been determined $10 \mathrm{~min}$ and $24 \mathrm{~h}$ post injection (Figure 5). On PET images acquired $24 \mathrm{~h}$ post injection, the liver, spleen, muscle and tumor display uptakes of $13 \pm 1 \% \mathrm{ID} / \mathrm{g}, 14 \pm 2 \% \mathrm{ID} / \mathrm{g}, 0.4 \pm 0.1 \% \mathrm{ID} / \mathrm{g}$ and $6 \pm 2 \% \mathrm{ID} / \mathrm{g}$, respectively. Compatible results have recently been published for stealth liposomes, ${ }^{5,6,12}$ which demonstrate that the in vivo performance of liposomes loaded using the UAL method remains unchanged. The estimated blood circulation half-life of $9.7 \mathrm{~h}$ in mice is in agreement with earlier reports, ${ }^{11,12,23}$ and that no leakage of ${ }^{64} \mathrm{Cu}$ DOTA from liposomes is observed in mice plasma (Figure S1). Together, these results substantiate the in vivo stability of liposomes loaded with ${ }^{64} \mathrm{Cu}$ using the UAL method.

Liposomes loaded with ${ }^{64} \mathrm{Cu}^{2+}$ using the UAL method was furthermore administered to a single canine cancer model. From PET/CT images, liposomes are found to accumulate in the spleen, liver and heart region $24 \mathrm{~h}$ post injection as expected. The accumulation in organs and tissues $24 \mathrm{~h}$ post injection has been determined via PET images, and SUVs of 3.8, 2.5 and 0.2 have been determined for the liver, spleen and muscle respectively. The blood clearance profile (Figure 6C) was determined upon administration of a single lipid dose $(4.3 \mathrm{mg} \mathrm{lipid} / \mathrm{kg})$, which shows that more than $75 \%$ of the injected dose to be present in blood pool at the time of injection. The obtained circulation half-life of $24 \mathrm{~h}$, moreover, agrees with recent findings by Susuki and co-workers, who, upon administration of pegylated liposomes $\left(6.7 \mu \mathrm{mol}\right.$ lipid/kg / $5 \mathrm{mg}$ lipid/kg), found an average half-life of $26 \mathrm{~h}$ in beagle dogs. ${ }^{32}$

With the increased recognition of the limitations in the use of SPECT for clinical liposome based imaging systems, improved radiolabeling methods are warranted and especially methods useful in PET imaging are needed. The unassisted ${ }^{64} \mathrm{Cu}^{2+}$ loading method and the in vivo performance of the ${ }^{64} \mathrm{Cu}-$ 
liposomal PET radiotracer presented here could eventually be useful in future clinical diagnostic and theranostic applications. ${ }^{64} \mathrm{Cu}$-loaded liposomes have several interesting future applications, and imaging studies in mice and canine cancer models could potentially provide more knowledge on how liposomal technology can be used in medical diagnostic and therapeutic applications. In clinical application, ${ }^{64} \mathrm{Cu}-$ liposomes could potentially be useful in liposomal drug development, in cancer diagnostic imaging and in various nano-theranostic applications such as in personalized medicine. ${ }^{1,2}$

\section{Conclusion}

We have successfully developed a highly efficient method for loading the PET radionuclide ${ }^{64} \mathrm{Cu}^{2+}$ into liposomes. The new UAL method relies on unassisted transport of copper ions across the lipid bilayer of liposomes entrapping a chelator. We demonstrate highly efficient loading ( $>95 \%)$ for a range of lipid formulations, which suggests that copper forms a neutral specie capable of crossing the liposomal bilayer. We show that loading kinetics is highly temperature dependent contrary to the previously reported IAL loading method using $2 \mathrm{HQ}$, and furthermore that stealth liposomes can be loaded (unassisted) with large quantities of copper. Once loaded, copper is shown to be present as a Cu-DOTA complex in oxidation state +2 , pointing to the conclusion that $\mathrm{Cu}^{2+}$ ions cross the lipid bilayer and are trapped by the entrapped chelator.

${ }^{64} \mathrm{Cu}$-liposomes prepared by UAL show high tumor accumulation in mice and long-term blood circulation in a canine cancer model in agreement with previous biodistribution reports on the liposomal formulation. We observe that liposomes prepared by UAL or IAL have equivalent biodistribution and stability in vitro and in vivo.

This new $\mathrm{Cu}^{2+}$ unassisted loading method is simple, cost-efficient, robust, and highly thermodynamic stable with respect to radionuclide retention, contrary to surface chelation strategies that require tailored synthesis of lipid-chelator analogues and may suffer activity loss due to transmetallation 
or migration of lipidated chelators in vivo. The loading stability of the UAL method is superior to other remote loading strategies that rely on $\mathrm{pH}$ or other chemical gradients, due to the high binding affinity of DOTA, which is a strong asset of the new method.

Contrary to what has been common knowledge and practice in the field of radionuclide liposome loading, we have developed an extremely simple and powerful tool for loading ${ }^{64} \mathrm{Cu}^{2+}$ into liposomes without use of ionophores. The method provides ${ }^{64} \mathrm{Cu}$-liposomes with superior imaging properties due to the protected location of ${ }^{64} \mathrm{Cu}^{2+}$ inside the liposomes, which prohibits ${ }^{64} \mathrm{Cu}^{2+}$ exchange with the biological environment due to the protective barrier constituted by the liposome membrane. Thus, the ${ }^{64} \mathrm{Cu}-$ liposomes constitute a highly sensitive PET tracer useful in characterizing in vivo performance of liposome based nanomedicine with great potential in clinical cancer diagnostic imaging applications as well as in various theranostic applications. 


\section{Author Information}

\section{Corresponding Authors}

* E-mail: thomas.andresen@nanotech.dtu.dk

Notes: The authors declare no competing financial interest.

\section{Acknowledgements}

The Danish Strategic Research Council, the Technical University of Denmark (DTU), the Danish National Advanced Technology Foundation, European Research Council (ERC) and the Lundbeck Foundation kindly provided financial support of this project.

\section{Associated content:}

Supporting information available: Additional figure and description on in vitro stability experiments. This material is available free of charge via the Internet at http://pubs.acs.org. 


\section{References}

(1) Lee, H.; Cheng, J.; Gaddy, D.; Orcutt, K. D.; Leonard, S.; Geretti, E.; Hesterman, J.; Harwell, C.; Hoppin, J.; Jaffray, D. A.; Wickham, T.; Hendriks, B. S.; Kirpotin, D. A Gradient-loadable ${ }^{64} \mathrm{Cu}-$ chelator for Quantifying Tumor Deposition Kinetics of Nanoliposomal Therapeutics by Positron Emission Tomography. Nanomedicine: NBM 2015, 11, 155-165.

(2) Petersen, A. L.; Hansen, A. E.; Gabizon, A.; Andresen, T. L. Liposome Imaging Agents in Personalized Medicine. Adv. Drug Delivery Rev. 2012, 64, 1417-1435.

(3) Goins, B. A. Radiolabeled Lipid Nanoparticles for Diagnostic Imaging. Expert Opin. Med. Diagn. 2008, 2, 853-873.

(4) Gabizon, A.; Huberty, J.; Straubinger, R. M.; Price, D. C.; Papahadjopoulus, D. An Improved Method for In Vivo Tracing and Imaging of Liposomes using a Gallium 67- Deferoxamine Complex. J. Liposome Res. 1988, 1, 123-135.

(5) Seo, J. W.; Mahakian, L. M.; Kheirolomoom, A.; Zhang, H.; Meares, C. F.; Ferdani, R.; Anderson, C. J.; Ferrara, K. W. Liposomal Cu-64 Labeling Method using Bifunctional Chelators: Polyethylene Glycol Spacer and Chelator Effects. Bioconjugate Chem. 2010, 21, 1206-1215.

(6) Seo, J. W.; Qin, S.; Mahakian, L. M.; Watson, K. D.; Kheirolomoom, A.; Ferrara, K. W. Positron Emission Tomography Imaging of the Stability of Cu-64 Labeled Dipalmitoyl and Distearoyl Lipids in Liposomes. J. Controlled Release 2011, 151, 28-34.

(7) Bao, A.; Goins, B.; Klipper, R.; Negrete, G.; Phillips, W. Direct ${ }^{99 m}$ Tc Labeling of Pegylated Liposomal Doxorubicin (Doxil) for Pharmacokinetic and Non-Invasive Imaging Studies. $J$. Pharmacol. Exp. Ther. 2004, 308, 419-425 
(8) Boerman, O.; Storm, G.; Oyen, W.; Vanbloois, L.; Vandermeer, J.; Claessens, R.; Crommelin, D. J.; Corstens, F. H. Sterically Stabilized Liposomes Labeled with In-111 to Image Focal Infection. $J$. Nucl.Med. 1995, 36, 1639-1644.

(9) Hwang, K.; Merriam, J.; Beaumier, P.; Luk, K. Encapsulation, with High-efficiency, of Radioactive Metal-ions in Liposomes. Biochim. Biophys. Acta 1982, 716, 101-109.

(10) Mougin-Degraef, M.; Jestin, E.; Bruel, D.; Remaud-Le Saec, P.; Morandeau, L.; Faivre-Chauvet, A.; Barbet, J. High-activity Radio-iodine Labeling of Conventional and Stealth Liposomes. J. Liposome Res. 2006, 16, 91-102.

(11) Wang, H-E.; Yua, H-M.; Lua, Y-C.; Heishe, N-N.; Tseng, Y-L.; Huang, K-L.; Chuang, K-T.; Chen, C-H.; Hwang, J-J.; Lin, W-J.; Wang, S-J.; Ting, G.; Whang-Peng, J.; Deng, W-P. Internal Radiotherapy and Dosimetric Study for ${ }^{111} \mathrm{In} /{ }^{177}$ Lu-pegylated Liposomes Conjugates in Tumorbearing Mice. Nucl. Instrum. Methods Phys. Res., Sect. A. 2006, 569, 533-537.

(12) Petersen, A. L.; Binderup, T.; Rasmussen, P.; Henriksen; J. R.; Elema, D. R.; Kjær, A.; Andresen, T. L. ${ }^{64} \mathrm{Cu}$ Loaded Liposomes as Positron Emission Tomography Imaging Agents. Biomaterials 2011, $32,2334-2341$.

(13) Locke L. W.; Mayo M. W.; Yoo A. D.; Williams M. B.; Berr S. S. PET Imaging of Tumor Associated Macrophages using Mannose Coated ${ }^{64} \mathrm{Cu}$ Liposomes. Biomaterials 2012, 33, 77857793.

(14) Kart, A.; Bilgili, A. Ionophore Antibiotics: Toxicity, Mode of Action and Neurotoxic Aspect of Carboxylic Ionophores. J. Anim. Vet. Adv. 2008, 7, 748-751.

(15) Hauser, H.; Phillips, M. C.; Stubbs, M. Ion Permeability of Phospholipid Bilayers. Nature 1972, 239, $342-344$. 
(16) Mills, J. K.; Needham, D. Lysolipid Incorporation in Dipalmitoylphosphatidylcholine Bilayer Membranes Enhances the Ion Permeability and Drug Release Rates at the Membrane Phase Transition. Biochim. Biophys. Acta 2005, 1716, 77-96.

(17) Papahadjopoulos, D.; Nir, S.; Ohki, S. Permeability Properties of Phospholipid Membranes: Effect of Cholesterol and Temperatures. Biochim. Biophys. Acta 1971, 266, 561-583.

(18) Paula, S.; Volkov, A. G.; Deamer, D. W. Permeation of Halide Anions through Phospholipid Bilayers occurs by the Solubility-diffusion Mechanism. Biophys. J. 1998, 74, 319-327.

(19) Carlson, S.; Clausén, M.; Gridneva, L.; Sommarin, B.; Svensson, C. XAFS Experiments at Beamline I811, MAX-lab synchrotron source, Sweden. J. Synchrotron Radiat. 2006, 13, 359-364.

(20) Frankær, C. G.; Harris, P.; Ståhl, K. A Sample Holder for In-house X-ray Powder Diffraction Studies of Protein Powders. J. Appl. Crystallogr. 2011, 44, 1288-1290.

(21) Ressler, T. WinXAS: A Program for X-ray Absorption Spectroscopy Data Analysis under MSWindows. J. Synchrotron Radiat. 1998, 5, 118-122.

(22) Joly, Y. X-ray Absorption Near-edge Structure Calculations beyond the Muffin-tin Approximation. Phys. Rev. 2001, 63, 1251201-1251210.

(23) Petersen, A. L.; Binderup, T.; Jølck, R. I.; Rasmussen, P.; Henriksen, J. R.; Pfeifer, A. K.; Kjær, A.; Andresen, T. L. Positron Emission Tomography Evaluation of Somatostatin Receptor Targeted ${ }^{64} \mathrm{Cu}-$ TATE-Liposomes in a Human Neuroendocrine Carcinoma Mouse Model. J. Controlled Release 2012, 160, 254-263.

(24) Kau, L. S.; Spira-Solomon, D. J.; Penner-Hahn, J. E.; Hodgson, K. O.; Solomon, E. I. X-ray Absorption Edge Determination of the Oxidation State and Coordination Number Application to the 
Type 3 site in Rhus-vernicifera Laccase and its Reaction with Oxygen. J. Am. Chem. Soc. 1987, 109, 6433-6442.

(25) Frank, P.; Benfatto, M.; Szilagyi, R. K.; D’Angelo, P.; Della Longa S, Hodgson K. O. The Solution Structure of $[\mathrm{Cu}(\mathrm{aq})](2+)$ and its Implications for Rack-Induced Bonding in Blue Copper Protein Active Sites. Inorg. Chem. 2007, 46, 7684-7684.

(26) Grice, J. D.; Szymanski, J. T.; Jambor, J. L. The Crystal Structure of Clinoatacamite, a New Polymorph of $\mathrm{Cu}-2(\mathrm{OH})(3) \mathrm{Cl}$. Can. Mineral. 1996, 34, 73-78.

(27) Riesen, A.; Zehnder, M.; Kaden, T. A. Metal-Complexes of Macrocyclic Ligands 24. Binuclear Complexes with Tetraazamacrocycle-N,N',N",N"'-tetraacetic Acids. Helv. Chim. Acta 1986, 69, 2074-2080.

(28) McLaughlin, S. The Electrostatic Properties of Membranes. Annu. Rev. Biophys. Biophys. Chem. 1989, $18,113-136$.

(29) Etzerodt, T.; Henriksen, J. R.; Rasmussen, P.; Clausen, M. H.; Andresen, T. L. Selective Acylation Enhances Membrane Charge Sensitivity of the Antimicrobial Peptide Mastoparan-X. Biophys. J. 2011, 100, 399-409.

(30) Powell, K. J.; Brown, P. L.; Byrne, R. H.; Gajda, T.; Hefter, G.; Sjöberg, S.; Wanner, H. Chemical Speciation of Environmentally Significant Metals with Inorganic Ligands. Pure Appl. Chem. 2007, $79,895-950$.

(31) Blust, R.; Bernaerts, F.; Linden, A. V.; Thoeye, C. In Artemia Research and its Application; Sorgeloos, P.; Bengtson, D. A.; Decleir, W.; Jaspers, E. Eds.; Universa Press: Wetteren, Belgium, 1987; pp. 311-323. 
(32) Suzukia, T.; Ichiharab, M.; Hyodoa, K.; Yamamotoa, E.; Ishidab, T.; Kiwada, H.; Ishihara, H.; Kikuchi, H. Accelerated Blood Clearance of PEGylated Liposomes Containing Doxorubicin upon Repeated Administration to Dogs. Int. J. Pharm. 2012, 436, 636-643. 
Table of Contents (TOC)

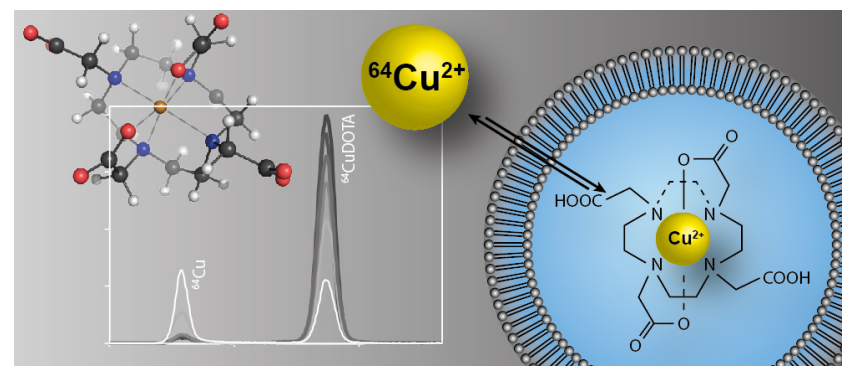




\section{Supporting information}

\section{Remote Loading of ${ }^{64} \mathrm{Cu}^{2+}$ into Liposomes without use of Ion Transport Enhancers}

Jonas R. Henriksen ${ }^{1,5}$, Anncatrine L. Petersen ${ }^{2,5}$, Anders E. Hansen ${ }^{2,3,5}$, Christian G. Frankarr ${ }^{1}$, Pernille Harris $^{1}$,Dennis R. Elema ${ }^{4,5}$, Annemarie T. Kristensen ${ }^{6}$, Andreas Kjar ${ }^{3}$ and Thomas L. Andresen ${ }^{2,5^{*}}$

${ }^{1}$ Technical University of Denmark, Department of Chemistry, Building 206, 2800 Lyngby, Denmark;

${ }^{2}$ Technical University of Denmark, Department of Micro- and Nanotechnology, Building 423, 2800

Lyngby, Denmark; ${ }^{3}$ University of Copenhagen, Faculty of Health Sciences, Department of Clinical Physiology, Nuclear Medicine \& PET and Cluster for Molecular Imaging, Rigshospitalet and University of Copenhagen, Blegdamsvej 3, 2200 Copenhagen N, Denmark; ${ }^{4}$ Technical University of Denmark, DTU Nutech, Hevesy Laboratory, Frederiksborgvej 399, 4000 Roskilde, Denmark; ${ }^{5}$ Center for Nanomedicine and Theranostics, Technical University of Denmark, 2800 Lyngby, Denmark; ${ }^{6}$ Department of Veterinary

Clinical and Animal Sciences, Faculty of Health and Medical Sciences, University of Copenhagen, Dyrlægevej 16, 1870 Frederiksberg C, Denmark.

*Corresponding author: Tel: +45 45258168; E-mail: thomas.andresen@nanotech.dtu.dk 


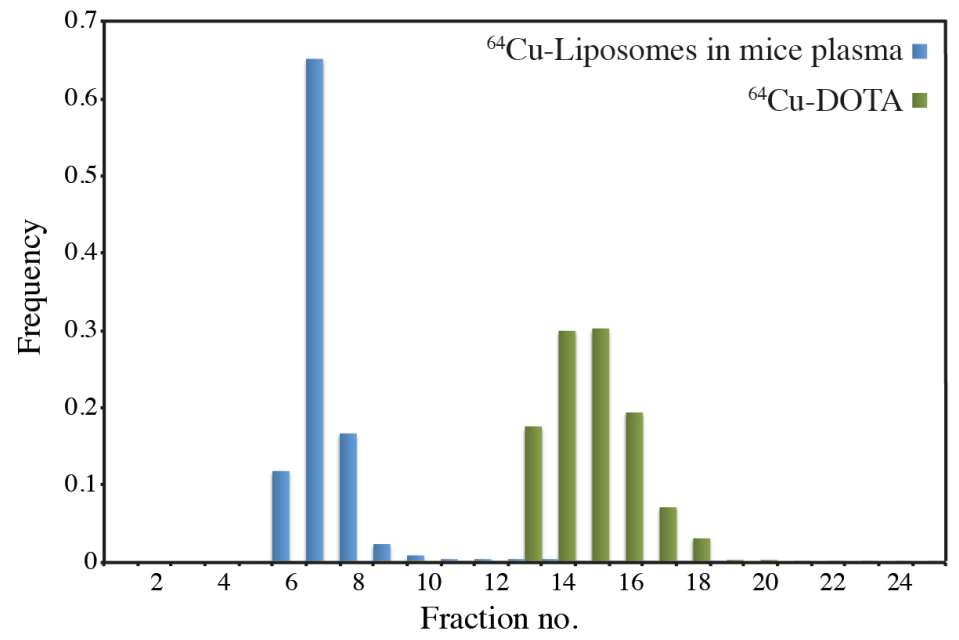

Figure S1. In vitro stability of ${ }^{64} \mathrm{Cu}$ loaded HSPC:CHOL:DSPE-PEG 2000 (56.5:38.2:5.3) liposomes in mice plasma. Size exclusion chromatograms are shown for liposomes that have been incubated for $18 \mathrm{~h}$ at $37^{\circ} \mathrm{C}$ in mice plasma (blue), and for ${ }^{64} \mathrm{Cu}$-DOTA as control (green). 